\title{
Tropical air-sea interaction in general circulation models
}

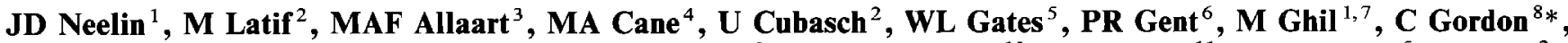 \\ NC Lau ${ }^{9}$, CR Mechoso ${ }^{1}$, GA Meehl ${ }^{6}$, JM Oberhuber ${ }^{2}$, SGH Philander ${ }^{10}$, PS Schopf ${ }^{11}$, KR Sperber ${ }^{5}$, A Sterl ${ }^{2}$, \\ T Tokioka ${ }^{12}$, J Tribbia ${ }^{6}$, and SE Zebiak ${ }^{4}$ \\ ${ }^{1}$ Department of Atmospheric Sciences, University of California, Los Angeles, CA 90024, USA \\ ${ }^{2}$ Max-Planck-Institut für Meteorologie, W-2000 Hamburg, FRG \\ ${ }^{3}$ Koninklijk Nederlands Meteorologisch Instituut, De Bilt, Nederland \\ ${ }^{4}$ Lamont-Doherty Geological Observatory, Palisades, NY 10964, USA \\ ${ }^{5}$ Lawrence Livermore National Laboratory, Livermore, CA 94550, USA \\ ${ }^{6}$ National Center for Atmospheric Research Boulder, CO 80307, USA \\ ${ }^{7}$ Institute of Geophysics and Planetary Physics, University of California, Los Angeles, CA 90024, USA \\ ${ }^{8}$ Meteorological Unit, Hooke Institute for Atmospheric Research, Clarendon Laboratory, University of Oxford, Oxford, OXI 3PU, UK \\ ${ }^{9}$ Geophysical Fluid Dynamics Laboratory, Princeton, NJ 08542, USA \\ ${ }^{10}$ Atmospheric and Oceanic Sciences Program, Princeton University, Princeton, NJ 08542, USA \\ ${ }^{11}$ Laboratory for Hydrospheric Processes, NASA Goddard Space Flight Center, Greenbelt, MD 20771, USA \\ ${ }^{12}$ Meteorological Research Institute, 1-1 Nagamine, Tsukuba, Ibaraki 305, Japan
}

Received April 15, 1991/Accepted August 4, 1991

\begin{abstract}
An intercomparison is undertaken of the tropical behavior of 17 coupled ocean-atmosphere models in which at least one component may be termed a general circulation model (GCM). The aim is to provide a taxonomy-a description and rough classification-of behavior across the ensemble of models, focusing on interannual variability. The temporal behavior of the sea surface temperature (SST) field along the equator is presented for each model, SST being chosen as the primary variable for intercomparison due to its crucial role in mediating the coupling and because it is a sensitive indicator of climate drift. A wide variety of possible types of behavior are noted among the models. Models with substantial interannual tropical variability may be roughly classified into cases with propagating SST anomalies and cases in which the SST anomalies develop in place. A number of the models also exhibit significant drift with respect to SST climatology. However, there is not a clear relationship between climate drift and the presence or absence of interannual oscillations. In several cases, the mode of climate drift within the tropical Pacific appears to involve coupled feedback mechanisms similar to those responsible for El Niño variability. Implications for coupled-model development and for climate prediction on seasonal to interannual time scales are discussed. Overall, the results indicate considerable sensitivity of the tropical coupled ocean-atmosphere system and suggest that the simulation of the warm-pool/cold-tongue configuration in the equatorial Pacific represents a challenging test for climate model parameterizations.
\end{abstract}

\footnotetext{
* Current affiliation: Hadley Centre/Meteorological Office, Bracknell, Berkshire, RG12 2SZ, UK

Offprint requests to: $\mathrm{D}$ Neelin
}

\section{Introduction}

\section{Prefacing remarks}

Large-scale air-sea interaction plays a crucial role in climate change and variability on a broad range of time scales. The development of coupled ocean-atmosphere models is thus widely regarded as essential for the simulation, understanding and prediction of the global climate system. Such models are currently being developed and tested at a number of institutions worldwide. Although these efforts typically benefit from years of previous work with atmospheric and oceanic models in uncoupled mode, coupling the two components represents a major step because of the new interactions introduced into the system. A large part of coupled-modeling activity has focused on tropical air-sea interactions because of the importance of interannual climate phenomena arising from these. Simulation of the tropical climatology is significant, even for models which are not primarily concerned with tropical phenomena, because of the important role which the tropics play in global climate.

Discussions following the Hamburg International Conference on Modeling of Global Climate Change and Variability of September, 1989, and subsequent discussions with various individual investigators, have suggested the usefulness of an intercomparison of current results of coupled ocean-atmosphere general circulation models (coupled GCMs or CGCMs) for tropical air-sea interaction. Although many of the investigations in this area are still in their early stages, a wide variety of behaviors have been noted and circulated informally within the community. The aim of this paper is to provide a taxonomy of these results - a description and rough classification - of interannual phenomena across the ensemble of models. The objective is analogous to 
zoological or botanical taxonomy; the structure of the models is known and a preliminary diagnosis of the anatomy of the interannual variability can be made, but the mechanisms and relationships between the phenomena found in different models are poorly understood. By assembling as many of these results as possible in a unified format, it is hoped that a classification by similarities and differences will suggest possible links between them. This in turn should provide the basis for future work both on understanding physical mechanisms and on model improvement.

A substantial fraction of the results included in this taxonomy have not yet been published elsewhere; in other cases results have been published and are summarized here specifically for intercomparison. All contributors are listed as authors. The two lead authors have undertaken the task of collecting the results of the contributing authors and of assembling the material into as coherent a form as possible. In describing models, results and hypothesized mechanisms, an effort has been made to remain faithful to the description of the contributing authors, while pointing out suggestive connections between them in cases where different explanations are offered for possibly related phenomena. Wherever possible, references to more extensive descriptions of models and phenomena are given. Any errors or omissions, as well as the particular choice of classification scheme under which the results are presented, remain the responsibility of the lead authors.

Sea surface temperature (SST) is chosen as the primary variable for intercomparison due to its crucial role in mediating the coupling and because it is a sensitive indicator of climate drift. Most attention is devoted to the Pacific Ocean because of the larger number of modeling results available. Figures of temporal evolution of the SST field along the equator are presented for each model with other aspects of the behavior described in the text. For models where coherent interannual variability of weak amplitude is found, figures of SST anomalies are very helpful in the interpretation but are omitted for brevity.

The focus is restricted to models in which at least one component may be termed a GCM. A general circulation model is taken to mean a model based on the primitive equations, in most cases simulating its own climatology, usually with several vertical degrees of freedom and, in the case of an atmospheric GCM (AGCM), having detailed parameterizations of radiative, convective and mixing effects. Coupled GCMs may be expected to suffer from common problems and deficiencies on the one hand, and similar long term potential on the other. However, the boundary between the CGCMs and a class of models based on modified shallow-water equations is not sharp. Results from the most widely known representative of this class, the Cane and Zebiak (1985) model, are included to provide a basis of comparison. Although we have attempted to include all CGCMs worldwide for which extended integrations exist, a number of models are unfortunately not represented, especially those developed since contributions were originally solicited.
The phenomena noted in the CGCM simulations do not always correspond to the observed tropical oceans but are nonetheless of considerable interest to coupled modelers. They serve as an indication of the richness of possible tropical phenomena and as a measure of what may be expected when atmospheric and oceanic models -each appearing reasonably realistic when run individually-are combined into a coupled system. This comparison of early modeling results may thus be considered a sensitivity study of the coupled system to differences in parameters, model formulation and modeling assumptions. The coupled system represents in many ways a much more stringent test of the individual components than does simulation in uncoupled mode because many negative feedbacks, such as those produced by the use of fixed-SST boundary conditions in the case of an AGCM, are weakened and some positive feedbacks are introduced. The results of coupled integrations thus often suggest refinements for the individual components. Many of the models presented here have undergone further development since these results were collected.

Finally, we note that there exist several groupings of papers in which a number of coupled models are collected, including the proceedings of the Liège meetings (Nihoul 1985; Nihoul and Jamart 1990), the Proceedings of the International TOGA Conference (World Climate Research Programme, 1990), the proceedings of a Royal Society of London conference (Charnock and Philander 1989) and a review of global coupled models presented at the Hamburg conference (Meehl 1990b). Other, more extensive, intercomparison efforts for atmospheric and oceanic GCMs (AGCMs and OGCMs) are currently underway, notably under the auspices of the Working Group on Numerical Experimentation (WGNE) of the World Climate Research Program (Boer et al. 1991 submitted to $\mathrm{J}$ Geophys Res) and the Numerical Experimentation Group of the Tropical Atmosphere-Global Ocean Program (TOGA/NEG). An intercomparison of cloud-climate feedback in 14 AGCMs has been published by Cess et al. (1989) and of AGCM radiation codes by Ellingson and Fouquart (1990). It is hoped that such systematic and detailed intercomparisons will also be carried out for coupled models as the field matures.

\section{Background}

The most prominent climate signal in the tropics on interannual time scales is the El Niño/Southern Oscillation phenomenon (ENSO) during which anomalous warm surface waters appear for a number of months in the central and eastern tropical Pacific. A classic description of ENSO evolution is outlined in Rasmusson and Carpenter (1982) and reviews and descriptions of this phenomenon from an observational point of view may be found, for instance, in Gill and Rasmusson (1983), Cane (1986), Philander (1990) and Deser and Wallace (1990). An indication of the significance of such tropical Pacific anomalies to global surface temperature variability may be found in Pan and Oort (1991) and Ghil and Vautard (1991). 


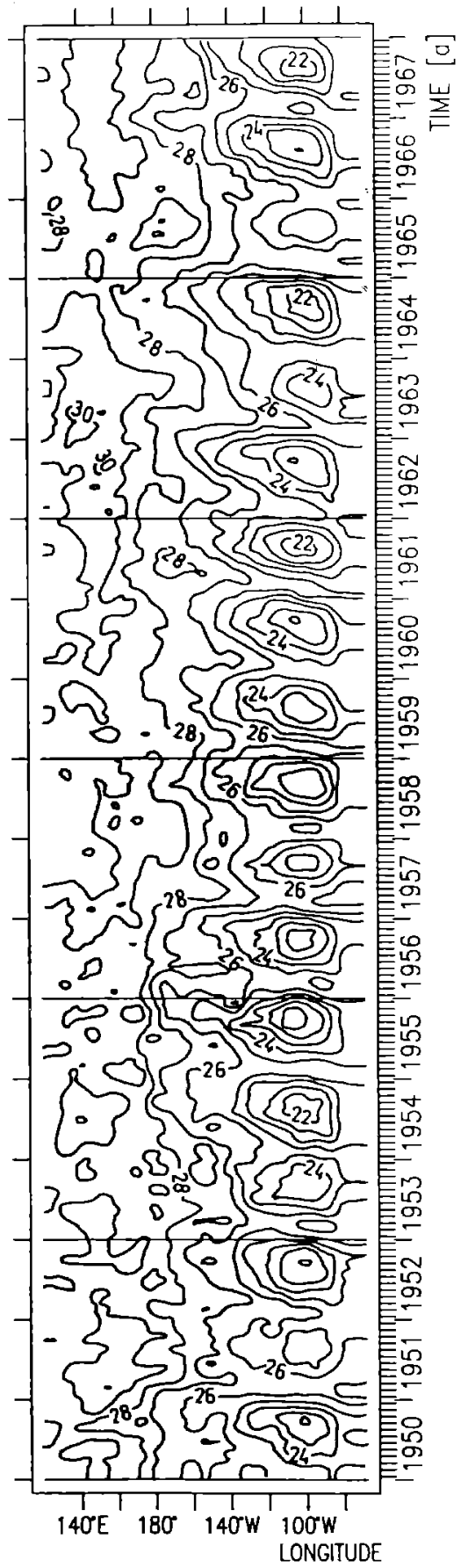

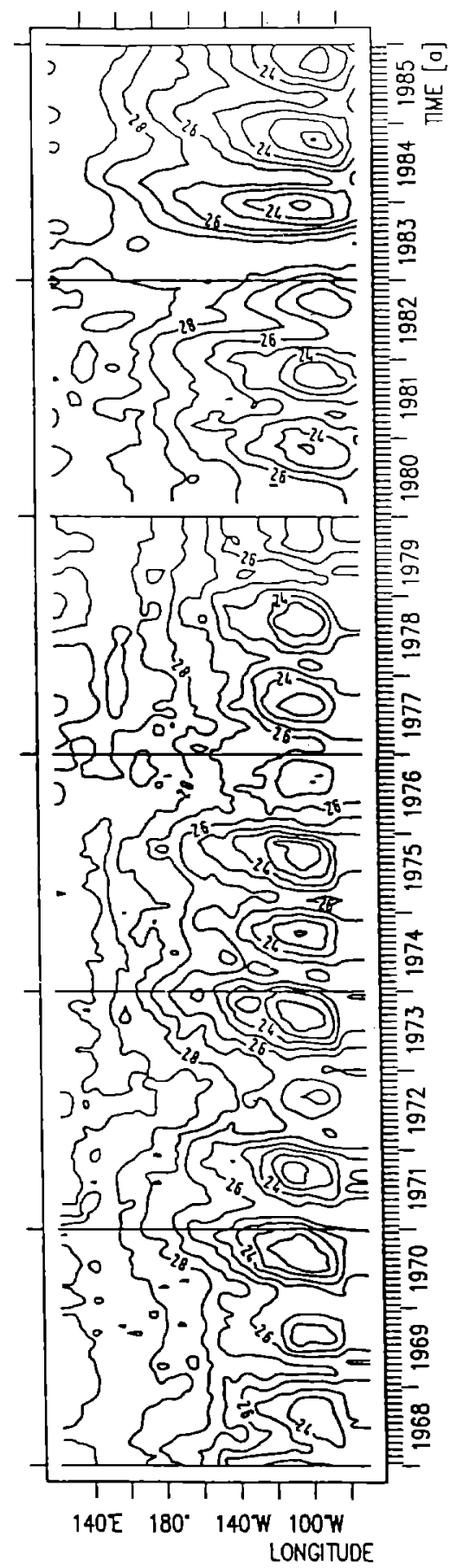

Fig. 1. Observed Pacific SST along the equator from 1950 through 1985 . Monthly mean data from 1950 through 1979 is from COADS, from 1980 through 1985 from NMC. Contour interval $1^{\circ} \mathrm{C}$. Figure courtesy of Yi Chao (after Chao 1990)
We provide for reference time-longitude diagrams of observed total SST in the Pacific from 1950 to 1985 in Fig. 1. The dominant features are the annual and interannual variations of the equatorial cold tongue in the east-central Pacific. It reaches a minimum temperature of about $22^{\circ} \mathrm{C}$ in the northern autumn and weakens considerably in northern spring according to the changes in the trade winds which produce the equatorial upwelling of subsurface water by Ekman drift off the equator. Since the pattern of the Trades and the positions of the Intertropical Convergence Zones tend to be determined by the pattern of SST (e.g., Graham and Barnett 1987; Wallace et al. 1989; Gutzler and Wood 1990 ), there is good reason to believe that the evolution of the seasonal cycle in the Pacific is itself strongly influenced by coupling between the atmosphere and ocean. An indication of this is the tendency of the seasonal maximum and minimum of SST to propagate westward along the equator (Horel 1982). In the western Pacific and Indonesian maritime-continent region, a warm pool of water exceeding $29^{\circ} \mathrm{C}$ may be found at all seasons.

The interannual signal associated with the aperiodic ENSO cycle is almost of comparable magnitude to the seasonal cycle and may be clearly seen in the total SST evolution. Rasmusson et al. (1990), and Lau and Sheu (1988) have documented both quasi-biennial and lower frequency 4-6 year components in this interannual var- 
iability. There is some suggestion of propagation of SST anomalies (eastward or westward) during some years, while in other years the SST anomalies tend to develop in place.

Although the ENSO mechanism is not yet fully understood, it is widely accepted that the evolution of anomalous conditions during ENSO results from a positive feedback between the tropical ocean and the tropical atmosphere, as first hypothesized on a descriptive basis by Bjerknes (1969). Although the complete study of ENSO requires the development of coupled ocean-atmosphere models, ENSO modeling started with the study of either the ocean or the atmosphere alone. Ocean models consisting of simple linear shallow-water models revealed the importance of internal equatorial waves in the adjustment of the upper ocean in response to changing boundary conditions (e.g., McCreary 1976; Cane and Sarachik 1977; Cane 1979a, b), a result which was obtained also from observational studies (e.g., Wyrtki 1975). When forced by observed winds, these models have been remarkably successful in hindcasting observed interannual changes in sea level (e.g., Busalacchi and O'Brien 1981). More recently, sophisticated OGCMs of the Pacific basin have been used to successfully simulate observed SST and current variations associated with ENSO (e.g., Philander and Seigel 1985).

The atmospheric response to anomalous heating or SST has been also studied with a great variety of models ranging from shallow water models (e.g., Gill 1980) to sophisticated atmospheric GCMs (e.g., Lau 1985; Palmer and Mansfield 1986; Mechoso et al. 1987; Shukla and Fennessy 1988 and references therein). It was shown that at least the response over the tropical Pacific could be realistically reproduced in the AGCMs when the observed changes in the boundary conditions were prescribed. Furthermore, these results indicate that the slowly varying oceanic boundary conditions induce the possibility of short-range climate predictability at lead times long compared to the natural predictability of weather phenomena. Further references may be found in Nihoul (1985) and Philander (1990).

Progress in oceanic and atmospheric ENSO modeling studies encouraged the development of coupled ocean-atmosphere models. Reviews of simple and intermediate model studies may be found in Hirst (1990), Zebiak (1990), McCreary and Anderson (1991) and Philander (1990). Linear instability studies by Philander et al. (1984), Hirst (1986, 1988) and Battisti and Hirst (1988) are among contributions toward understanding the processes which can generate interannual variability in coupled models, through instability of the mean climatic state. A conceptual model hypothesized by Schopf and Suarez (1988) has also received wide attention. According to this "delayed-action oscillator" model, the reversal between El Niño (warm) and La Niña (cold) conditions can be attributed to the propagation of internal equatorial waves and their reflection at meridional boundaries.

An alternative mechanism for tropical interannual variability, independent of equatorial wave dynamics, involves unstable modes related to the time derivative of the SST equation, referred to as "SST modes" by Neelin (1991) and also found in the study of Hirst (1988). The period of these modes is associated with zonal propagation of SST anomalies and they are supported by several contributing growth mechanisms. Recent work suggests a relationship between these two points of view, with the delayed oscillator and SST mode cases representing two extremes of coupled mode behavior.

The simple models employ a great number of assumptions in parameterizing complex processes. Among processes poorly represented are the nonlinearity of equatorial upwelling and surface-current/undercurrent dynamics, and atmospheric convective processes. It is hoped that coupled GCMs will eventually provide a more complete and accurate treatment of the dynamics and physics of ocean-atmosphere interaction. The strong dependence of interannual variability on parameters and the difficulties of understanding the exact mechanism even in the simple coupled models suggest that unraveling the sources of differences between coupled GCMs may be a long-term task. Nonetheless, there is sufficient progress to make this preliminary attempt worth undertaking.

\section{Model descriptions}

Table 1 presents a summary of the models, grouped by common characteristics in terms of resolution and physics. The category 'simple atmospheric models' broadly includes steady models with parameterized moist processes and time-dependent models with reduced physics relative to AGCMs. Atmospheric models are not classified by horizontal resolution; the AGCMs are all coarse in resolution relative to spatial scales of equatorial ocean dynamics and atmospheric intertropical convergence zones. The simple atmospheric models have finer resolution but are limited by the crudeness of the physical parameterizations. The models classified as 'low vertical resolution AGCMs' have only two vertical levels but 'full physics'-i.e., an extensive set of parameterizations of physical processes. The models listed as 'high vertical resolution AGCMs' generally have at least 9 levels (except Tokioka et al., which has 5) and full physical parameterization packages, with some exceptions as indicated in the descriptions.

The ocean models are essentially all GCMs based on the primitive equations with the exception of Cubasch et al. and Zebiak and Cane. These have been included in the relevant class according to resolution. The $\mathrm{Cu}$ basch et al. OGCM differs from the primitive equation OGCMs in its treatment of momentum advection and time stepping. While the Zebiak and Cane model is not generally considered a GCM, it includes nonlinear advection of SST anomalies and careful parameterization of other processes affecting SST. 'Low vertical resolution' is used to designate models with six vertical degrees of freedom or less, while the models listed as 'high vertical resolution' all have at least 10 and as 
Table 1. Summary of models grouped by common characteristics in terms of resolution and physics.

The category 'Simple atmospheric models' broadly includes steady models with parameterized moist processes and time-dependent models with reduced physics relative to AGCMs. Atmospheric models are not classified by horizontal resolution; the AGCMs are all coarse resolution relative to space scales of equatorial dynamics. Ocean models not based on the primitive equations have been included in the relevant class according to resolu- tion (see text for specification). Section numbers for the 'Model Descriptions' section are given in the upper left corner for each class. Corresponding categories are used in the 'Results' section. Only models for which complete Model Descriptions and Results sections are given in the text are listed here. Models or versions of models for which partial results are available are mentioned in the relevant sections or in the Discussion. Coordinating institutions are indicated in brackets for each effort

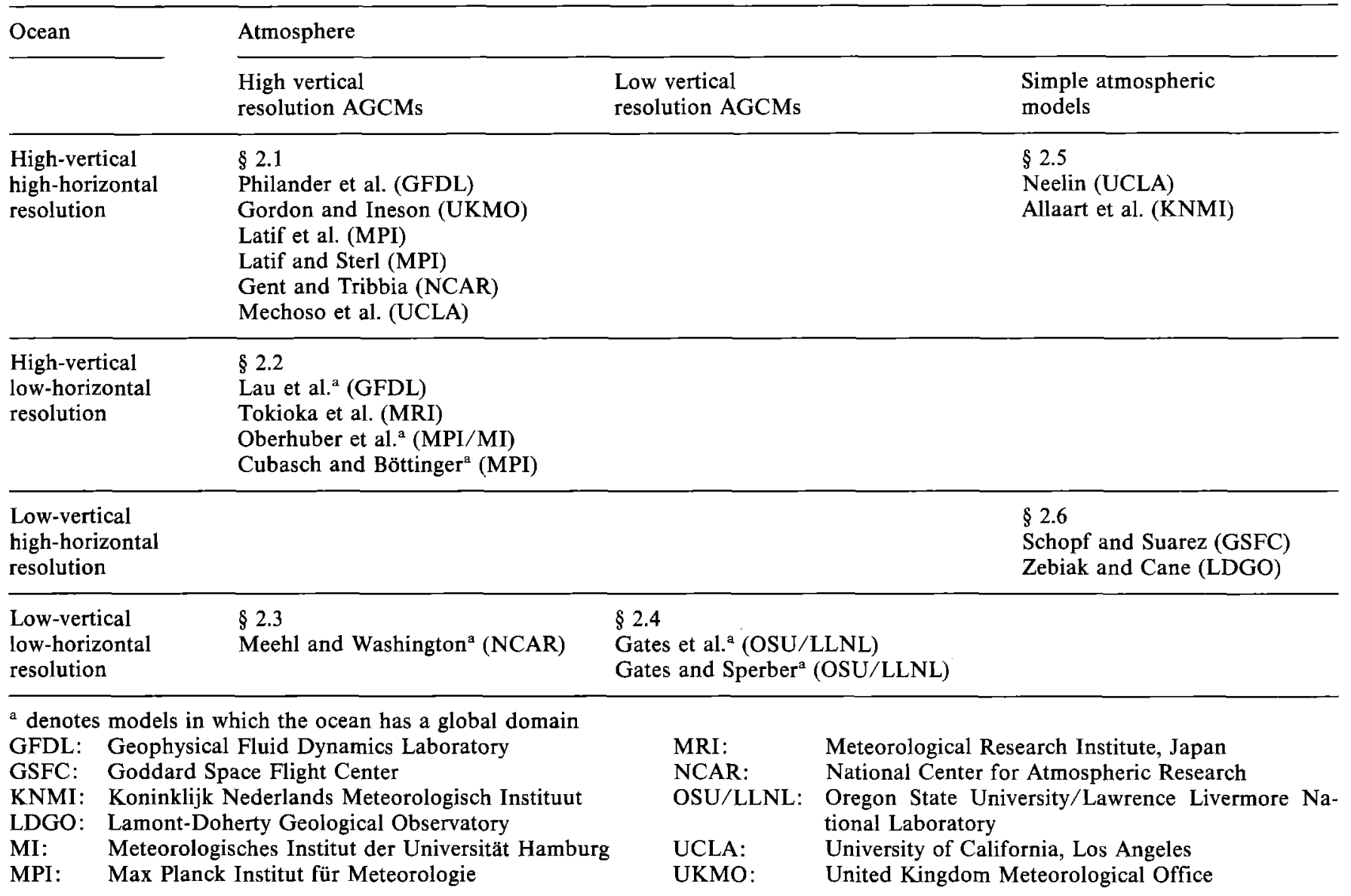

many as 27 vertical degrees of freedom (levels, layers or isopycnal surfaces). 'High horizontal resolution' denotes models with grid spacing of $1^{\circ}$ latitude or less in the equatorial waveguide. The parameterization of vertical mixing differs considerably between models, as described in the relevant sections. Not all models include active salinity. Some are limited domain models, others are global.

The variety of design in the models largely reflects the purposes for which they are intended. For instance, the choice of coarse resolution is motivated by the need to make integrations on the order of a century to investigate the effects of increasing greenhouse gases on global climate. The models indicated as having global ocean domains in sections 2.2, 2.3 and 2.4 of Table 1 are primarily designed for such applications. Many of these models have parameterizations of physical processes such as sea ice, which are omitted from the higherresolution models (section 2.1) designed primarily for the study of tropical air-sea interaction. The term "hybrid coupled model" is used for the models (section
2.5) consisting of an ocean GCM coupled to a much simpler atmospheric model, especially one which attempts to represent the steady-state atmospheric response to oceanic conditions. The intent is to understand some of the phenomena and some of the difficulties which may be encountered in coupled GCMs in a model in which the coupled system is not affected by "noise" arising from atmospheric variability that does not depend on the coupling. The models of section 2.6 in Table 1 are potentially less complex to analyze and have smaller computational requirements, making ensembles of long runs for parameter testing and predictability assessment more feasible. The term "intermediate coupled model" is sometimes applied to models of this class.

Some models use correction techniques to limit climate drift of the coupled system due to systematic errors in one or both components. We use the terminology 'flux correction' to refer to such techniques, of which there are several variants. The term 'anomaly model' is used for models formulated explicitly in 
terms of anomaly variables, in particular that of Zebiak and Cane. The distinction between these approaches is not sharply defined since flux correction in essence makes at least one component of a fully nonlinear model into an anomaly model.

The 'Model Descriptions' section is structured according to the section numbers indicated in the upper left hand corner of each box in Table 1. The 'Results' section follows this same order. Where more than one integration has been carried out with closely related versions of a model, we denote these as Run-1, Run-2 and so forth.

\subsection{Multi-level AGCMs with high-resolution OGCMs}

\section{a) Philander, Lau and Pacanowski}

The atmospheric model is the Geophysical Fluid Dynamics Laboratory (GFDL) Climate Dynamics Project spectral model (Manabe and Hahn 1981), with rhomboidal 15 (R15) truncation and 9 layers in the vertical. Convection is represented by convective adjustment, but cloud cover is prescribed as a function of latitude and pressure in the radiative code in the main version presented here. The atmospheric model is known to yield a realistic response to prescribed observed SST patterns, as described by Lau (1985).

The oceanic model is restricted to the tropical $\mathrm{Pa}$ cific region with a domain extending from $28^{\circ} \mathrm{S}$ to $50^{\circ} \mathrm{N}$ and $130^{\circ} \mathrm{E}$ to $80^{\circ} \mathrm{W}$ with maximum horizontal resolution of $\frac{1}{3}^{\circ}$ by $1^{\circ}$. There are 27 vertical levels, the upper $100 \mathrm{~m}$ having a resolution of $10 \mathrm{~m}$. Richardsonnumber-dependent vertical mixing is used as in Pacanowski and Philander (1981). The coefficients of horizontal eddy viscosity and diffusivity are $2 \times 10^{3} \mathrm{~m}^{2} \mathrm{~s}^{-1}$ equatorward of $10^{\circ}$ latitude and larger in the poleward regions. A Newtonian cooling is applied at high latitudes to return temperatures toward the observed Levitus (1982) values. The ocean model simulation of the seasonal cycle in the Pacific has been described in Philander et al. (1987) and the simulation of the 1982-83 El Niño in response to observed winds is described in Philander and Seigel (1985).

The two models are coupled synchronously with information being passed between them once per day. SST from the higher-resolution ocean model is averaged spatially over grid boxes corresponding to the atmospheric model in the coupling. SST outside the ocean model domain is specified from observations and ocean model SST is modified to ensure that there is no abrupt transition at-model boundaries which do not correspond to coastlines. No flux correction is applied. Annual average insolation is used so the model does not have diurnal or seasonal cycles. Further model description may be found in Philander et al. $(1989,1992)$. Initial conditions correspond to an atmosphere at rest and a tropical Pacific Ocean in equilibrium with the annual mean winds of Hellerman and Rosenstein (1983). The integration was carried out for 28 years.

\section{b) Gordon and Ineson}

The atmospheric component of the model is the latest version of the British Meteorological Office 11-layer climate model (Slingo et al. 1991). It has a $2.5^{\circ}$ latitude by $3.75^{\circ}$ longitude grid and contains a number of detailed physics packages-including interactive cloud. This model has been used for a variety of climate related studies (e.g., Palmer and Mansfield 1986). The surface fluxes produced by an earlier version of the atmospheric model which was integrated with SSTs specified from climatology are discussed in Gordon (1989a). Basically the wind stress and heat fluxes were within the uncertainty in these quantities in the observed climatologies. The only major difference in the later version of the atmospheric model used here is a reduction in the net heat input, due to an increased latent heat loss, over the west Pacific warm pool region. This was achieved by the inclusion of a parameterization of subgrid gustiness associated with convection.

The ocean model is a high-resolution version of the GFDL Cox model. It covers only the Pacific from $30^{\circ} \mathrm{N}$ to $30^{\circ} \mathrm{S}$ and has a non-uniform horizontal grid spacing with a resolution of $0.33^{\circ}$ of latitude on the equator and $0.5^{\circ}$ of longitude at the coasts. There are 16 levels in the vertical with a concentration of levels near to the ocean surface. The K-Theory mixing scheme of Pacanowski and Philander (1981) is included to represent shear-induced mixing and an embedded Kraus-Turner mixed-layer model to parameterize the effects of surface-generated turbulence on the mixed layer (Ineson and Gordon 1989). Earlier versions of this ocean model have been used to simulate the seasonal cycle (Gordon and Corry 1991) and the 1982/83 El Niño. The ocean model has an active salinity field.

Before starting the coupled integration, the ocean model was spun-up using the wind stress from a control version of the atmospheric model which had previously been integrated with climatological SSTs. The heat fluxes were chosen to ensure the SSTs remained close to their climatological values. At the start of the coupled integration the models were coupled fully via stress, heat fluxes and precipitation minus evaporation.

The earlier version of this coupled model has been described in Gordon (1989b). The principle differences between the old version and the new version are the addition of the Kraus-Turner mixed-layer representation in the OGCM and the gustiness parameterization in the AGCM heat fluxes. The results with the older version will be referred to as Run-1 and the run with the newer version, which is the main version presented here, will be referred to as Run-2.

\section{c) Latif, Biercamp, von Storch and Zwiers}

The design of the atmospheric model and its ability to reproduce the observed atmospheric circulation are described by Fischer (1987), Storch (1988) and Latif et al. (1990). This spectral model has triangular 21 (T21) truncation, the nonlinear terms and the parameterized phy- 
sical processes being calculated on the 64 by 32 point Gaussian grid which yields a horizontal resolution of about $5.6^{\circ}$. There are 16 levels in the vertical (19 levels in more recent applications) which are defined on sigma-surfaces in the lower troposphere and on pressuresurfaces in the upper troposphere and in the stratosphere. The model includes standard physics such as a full hydrological cycle, boundary layer parameterization and interactive cloud cover which affects radiative transfer. Versions of the same AGCM are used by the models described in sections $2.1 \mathrm{~d}, 2.2 \mathrm{c}$ and $2.2 \mathrm{~d}$ with different OGCMs. Differences between this model and the European Center for Medium Range Weather Forecasting (ECMWF) model (Louis 1986) from which it is derived are described in section $2.2 \mathrm{c}$.

The ocean model is a primitive equation model which resolves the tropical Pacific Ocean from $30^{\circ} \mathrm{N}$ to $30^{\circ} \mathrm{S}$ and from $130^{\circ} \mathrm{E}$ to $70^{\circ} \mathrm{W}$, described in detail in Latif (1987). The model includes real coastlines but does not incorporate bottom topography; the ocean floor is at a constant depth of $4000 \mathrm{~m}$. The zonal resolution is constant at $670 \mathrm{~km}$, while the meridional resolution is variable, increasing from $50 \mathrm{~km}$ near the equator to approximately $400 \mathrm{~km}$ at the boundaries. There are 13 levels in the vertical, ten of which are placed within the upper $300 \mathrm{~m}$ of the ocean. In contrast to Latif (1987), Richardson-number-dependent mixing coefficients (Pacanowski and Philander 1981) are adopted. The vertical eddy viscosity and eddy diffusivity were both assigned values of $20 \mathrm{~cm}^{2} \mathrm{~s}^{-1}$ under neutral conditions and have background values of 0.1 and 0.01 $\mathrm{cm}^{2} \mathrm{~s}^{-1}$, respectively. The horizontal eddy viscosity is constant with a value of $10^{8} \mathrm{~cm}^{2} \mathrm{~s}^{-1}$. Explicit horizontal heat diffusion is not included.

The ocean model is driven by turbulent surface momentum and heat fluxes which are computed by the atmospheric model. The atmospheric model in turn is influenced by SST, which is simulated over the tropical Pacific by the ocean model and specified from climatology elsewhere. Coupling is done synchronously every ocean time step, i.e., every two hours. As in the flux correction scheme suggested by Sausen et al. (1988), all three interactive quantities are corrected with seasonally varying offset values determined from uncoupled control runs which used climatological forcing. The integration begins on a January 1 , using atmospheric and oceanic initial fields simulated in the uncoupled model's runs. More detailed description of the coupled model is given in Latif et al. (1988b). A slightly different version of this model was used to investigate the response of the coupled system to wind bursts over the western Equatorial Pacific (Latif et al. 1988a). The same ocean model was also coupled to two simpler (linear) atmospheric models. Results can be found in Latif and Villwock (1990).

\section{d) Latif and Sterl}

The atmospheric model is an updated version of the T21 model described in the previous section. Preliminary results from a run with observed SSTs show no significant differences of the simulated tropical low-frequency response to those presented by Latif et al. (1990) for the earlier version.

The ocean model is similar to the one described by Latif et al. in the previous section. Here only the differences from this earlier version are described. The domain is zonally global and extends from $70^{\circ} \mathrm{N}$ to $70^{\circ} \mathrm{S}$. The meridional resolution is $0.5^{\circ}$ within $10^{\circ} \mathrm{N}$ to $10^{\circ} \mathrm{S}$, increasing to $1^{\circ}$ at $\pm 20^{\circ}$ and to $5^{\circ}$ between $\pm 30^{\circ}$ and $\pm 70^{\circ}$. Zonally the resolution is constant at $5^{\circ}$. In the vertical there are 17 levels with a resolution of $20 \mathrm{~m}$ in the upper $100 \mathrm{~m}$. Bottom topography is fully included as well as active salinity. Finally, the numerics have been changed to be less diffusive. The ocean model is dynamically active only in the region $\pm 30^{\circ}$ latitude. Outside this region a rather strong restoring to Levitus climatology is applied.

The two models interact over all three oceans in the $\pm 30^{\circ}$ latitude band. Outside the coupling region, the boundary conditions are prescribed from climatology. The coupled integration has a duration of 20 years and has been performed without applying any flux correction. The coupling is synchronous with an exchange of information every ocean time step, i.e., every two hours.

\section{e) Gent and Tribbia}

The atmospheric model used in the coupled experiments is a derivative of the NCAR Community Climate Model, Version 1 (CCM1) (Williamson et al. 1987). The model used here differs in the following respects. The lower surface of the model has been altered from the standard (Earth) continentality and replaced with a zonally symmetric inactive sea surface (aqua planet) except in the ocean model domain. The standard parameterizations of radiative fluxes used in CCM1 have been replaced by the following prodecure: time mean zonal averages of radiative fluxes for January are marched seasonally between hemispheres. These radiative fluxes are modified only over the active ocean surface in a manner similar to Seager et al. (1988), whenever the cloud parameterization in the model indicates the presence of nonzero cloud fraction. Lastly, the surface roughness $z_{0}$ is taken as $0.25 \mathrm{~m}$ over the inactive ocean and given a value of $0.0005 \mathrm{~m}$ over the active region in order to obtain surface wind speeds which are realistic over the active ocean domain.

The numerics of the atmospheric model are as in Williamson et al. (1987) in all respects except horizontal resolution. In order to resolve the tropical atmosphere adequately and still minimize computational expense, a cutoff $\mathrm{T} 42$ resolution was used. In this truncation, only those spectral components that are included at T42 and which have zonal wavenumber less than wave number 22 are included in the integration. Such a truncation gives the meridional resolution of T42 resolution necessitating the short time increment needed for the computational stability of the shorter zonal scales.

The ocean component is a reduced-gravity, primitive equation model. The average depth of the model is 
$400 \mathrm{~m}$; below that the ocean is at rest and has a constant density. Since the model does not have salinity, constant density also means constant temperature. The ocean has a mixed layer with a constant depth of $50 \mathrm{~m}$ and the active region below the mixed layer is divided into six more model layers using a sigma coordinate relative to the lower surface. Thus the vertical resolution is, on average, $50 \mathrm{~m}$. The horizontal domain is from $130^{\circ} \mathrm{E}$ to $80^{\circ} \mathrm{W}$ and from $30^{\circ} \mathrm{S}$ to $30^{\circ} \mathrm{N}$. The horizontal resolution in the coupled calculation is $1.5^{\circ}$ in longitude and variable in latitude. It is $0.25^{\circ}$ at the equator varying smoothly to $1^{\circ}$ at $30^{\circ} \mathrm{N}, \mathrm{S}$. Nonlinear computational instability in the model is controlled by use of a Shapiro filter which is of order 16 in the interior reducing to order 2 at the boundaries. The model also has Richardson-number-dependent vertical mixing. Full details of the model can be found in Gent and Cane (1989) and Gent (1991).

Coupling is done synchronously, with the components exchanging information every day.

\section{f) Mechoso, Ghil, Halpern, Fisher and Spahr}

The atmospheric model is the 9-1ayer, $4^{\circ}$ latitude by $5^{\circ}$ longitude version of the UCLA AGCM. This is a gridpoint model using the potential-enstrophy-conserving horizontal-differencing scheme of Arakawa and Lamb (1981), modified to give fourth-order accuracy for the advection of potential vorticity and potential temperature, and to preserve positive definiteness in advection of water vapor. Vertical differencing follows Arakawa and Suarez (1983), based on a modified sigma-coordinate system above the planetary boundary layer (PBL) top, and pressure coordinate above $100 \mathrm{mb}$. The PBL is modeled as a well-mixed, variable-depth, bottom layer employing bulk assumptions for the description of turbulence (Suarez et al. 1983) and using the bulk parameterization of Deardorff (1972) for surface fluxes of sensible heat, moisture and momentum. When the top of the PBL is above the condensation level, it has a sublayer of stratocumulus clouds which affects radiation fluxes at the surface. The parameterization of cumulus convection and its interaction with the PBL is based on Arakawa and Schubert (1974) and the effects of vertical redistribution of momentum by cumulus clouds are included. Effects of downdrafts on the PBL (Cheng and Arakawa 1991) are not included in the version of the model used here.

The model includes both diurnal and seasonal changes. Solar and infrared radiative heating rates are computed following Katayama (1972). The calculation includes the effects of absorption of solar radiation by ozone and water vapor, and absorption and emission of longwave radiation by ozone, water vapor and $\mathrm{CO}_{2}$ at levels below $30 \mathrm{~km}$. The cloudiness used in the radiation calculation is predicted by the model by assuming overcast conditions whenever the predicted relative humidity exceeds saturation at levels below $100 \mathrm{mb}$ or when cumulus clouds penetrate above $500 \mathrm{mb}$. More recent versions of the AGCM include the long-wave radiation calculation of Harshvardhan et al. (1987).
The ocean model is the GFDL model in a Pacific basin. The version used for the runs described here is essentially identical to that described in section 2.1a, using the Richardson-number-dependent vertical-mixing scheme of Pacanowski and Philander (1981). More recent versions of the OGCM employ a version of the Mellor-Yamada (1974) scheme (Rosati and Miyakoda 1988).

Coupling is synchronous within the Pacific basin with information exchanged each day between the models. Diurnal variation is averaged out in the ocean forcing in the present version. The geographical distributions of surface albedo, ground wetness and sea surface temperature outside the ocean model domain are interpolated from prescribed monthly means based on the observed climatology. Further description is given in Mechoso et al. (1990). Two runs are described here: one with full seasonal cycle and another with perpetual January conditions.

\subsection{Multi-level AGCMs with low-horizontal high-vertical resolution OGCMs}

\section{a) Lau, Philander and Nath}

The atmospheric model is the GFDL Climate Group GCM as described in section 2.1a. The ocean model is a version of the Bryan and Lewis (1979) model and is dynamically active throughout the world ocean. Model numerics are similar to the high-resolution version of the ocean model described in section 2.1a but the horizontal and vertical resolution are much lower: $3.75^{\circ}$ longitude by $4.5^{\circ}$ latitude with 12 levels in the vertical, the top 4 layers having thicknesses of $51,68,101$, and $151 \mathrm{~m}$. The vertical mixing coefficient is constant; the horizontal diffusion coefficient for momentum is $2.5 \times 10^{5} \mathrm{~m}^{2} \mathrm{~s}^{-1}$, about 100 times larger than the highresolution version.

A coupling algorithm designed by $S$. Manabe and $R$. Stouffer of the Climate Dynamics Project at GFDL was used. Oceanic and atmospheric boundary conditions are exchanged once per day and held fixed for the respective components during each day's integration. No seasonal cycle or diurnal cycle is included. Initial conditions for the run presented here are taken from a climate run which has been integrated asynchronously for 1250 ocean years to attain equilibrium (Manabe and Stouffer 1988). The integration was carried out for approximately 140 years.

\section{b) Tokioka, Endoh and Nagai}

The atmospheric model is a 5-level GCM with a resolution of $5^{\circ}$ longitude by $4^{\circ}$ latitude, described by Tokioka et al. (1984). It includes standard parameterizations of physical processes such as a boundary-layer parameterization following Randall (1976), the cumulus parameterization of Arakawa and Schubert (1974) and interactive cloud-radiation processes. 
The ocean model is a regional model of the tropical Pacific with realistic coastlines and a flat bottom at $4000 \mathrm{~m}$. It is based on the primitive equations and it has the same horizontal resolution as the atmospheric model. Vertically, there are 16 levels. Vertical mixing coefficients are calculated according to Pacanowski and Philander (1981).

The coupling is done synchronously, with daily-averaged wind stress, heat flux and fresh-water flux passed to the ocean and daily-averaged SST passed to the atmosphere. No correction is applied to the surface fluxes. The coupled model is driven with seasonally and daily varying insolation. Initial conditions for the atmospheric model have been taken from a run with climatological SST. The ocean is initially at rest with the stratification prescribed according to Levitus (1983) climatology. An outline of the model and a partial description of model performance are also given in Endoh et al. (1991). Experiments are also currently being conducted with a version of the model which has a high-resolution OGCM $-1^{\circ}$ latitude by $2.5^{\circ}$ longitude -and uses a vertical-mixing scheme based on Mellor and Yamada (1974).

\section{c) Oberhuber, Lunkeit and Sausen}

The atmosphere model (ECHAM) is a modified version of the T21 version of the ECMWF model (cycle 31, 19 vertical levels) which was developed for extended range forecasts. Since the model physics are constrained to present-day climate, e.g., the $\mathrm{CO}_{2}$ absorption and the transport of heat and water in the soil, a number of changes have been made to obtain a better representation of the climatology. The new model ECHAM (ECMWF with Hamburg physics) uses envelope orography, a new algorithm for radiative transfer in the infrared and a different scheme for cloud formation and dissipation with consideration of subgrid-scale effects, cloud microphysics and interaction of clouds and radiation, contains transport of water vapor, includes a parameterization for horizontal diffusion, computes the heat transfer in a 5-layer soil parameterization and uses the catchment consideration for the soil moisture content, considers effects of plants on evaporation and includes the diurnal cycle. Also changes have been made to the Kuo-convection scheme, the vertical diffusion and the gravity wave drag. Compared to the original ECMWF model version, the new ECHAM model shows considerable improvement in many basic quantities (Roeckner et al. 1989). The version used here is a more recent version of the AGCM described in section 2.1c.

The ocean general circulation model (OCPYC) was developed by Oberhuber (1991 submitted to J. Phys. Oceanogr.). The model uses isopycnal coordinates for the deep ocean. An active mixed layer represents the surface boundary layer. The model's resolution is the Gaussian grid corresponding to the T42 atmospheric model (about $2.8^{\circ} \times 2.8^{\circ}$ ) with 9 layers in the vertical. The domain is global and topography is included. The primitive equations are integrated in time with an implicit technique. A realistic equation of state is used, with temperature and salinity as active tracers. Wind stirring, buoyancy fluxes, internal dissipation and penetrative solar radiation are part of the mixed layer parameterization. Entrainment, detrainment, cross-isopycnal mixing and convective adjustment contribute to cross-isopycnal exchange.

The sea-ice model predicts momentum, concentration and thickness as basic quantities. A standard formulation for the thermodynamical forcing is taken. In addition the Hibler-like theology enables the model to predict realistic sea-ice covers and transports. Implicit techniques are used to formulate the model on the same grid and with the same time step as the ocean model. The ice model is coupled to the mixed layer.

Both directly-coupled and flux-corrected (Sausen et al. 1988) versions of the model have been tested. The atmosphere, ocean and sea-ice components are coupled synchronously. After each time step of 1 day of the ocean and ice model, the models exchange fluxes of heat, fresh water and momentum. In the flux-corrected version, these fluxes are corrected using climatological fields derived from reference runs of the atmosphere (20 years with 3 years of spin-up) and the ocean (after 250 years of spin-up). Over sea ice, additional operations are necessary to compute corrected values for the skin temperature under the constraint of a variable sea ice concentration. Results from the directly coupled version will be referred to as Run-1 and from the fluxcorrected version as Run-2.

\section{d) Cubasch and Böttinger}

The atmospheric model is the same 19 level, T21 version of the ECHAM model described in section 2.2c.

The ocean model is a large-scale geostrophic (LSG) global model developed by Maier-Reimer et al. (1982). It has implicit time stepping, permitting a time step of 1 day in the upper two layers and 30 days in the remainder of the ocean. An Arakawa E-grid is used, with the closest grid points to the equator at approximately $\pm 2^{\circ}$. The temperature equation includes full nonlinearity. The ocean model does not accurately describe equatorial wave dynamics but is able to simulate some aspects of interannual SST variability when forced with observed winds. The ocean model includes realistic bottom topography and a basic thermodynamic icemodel with advection of ice.

The coupled model was developed for the simulation of $\mathrm{CO}_{2}$ induced warming. Coupling is near-synchronous; values for total heat and fresh-water fluxes are accumulated and passed to the ocean every day, while the wind stress is accumulated and passed with a coupling step of 30 days. The ocean model returns the SST and the ice-thickness. Description of an earlier version of the coupled model and aspects of the coupling may be found in Cubasch et al. (1990). No flux correction has been applied in the current version. The coupled atmosphere model includes an ice model, which con- 
verts the ice thickness into a temperature on the top of the sea ice by a balance equation. No run-off has yet been included.

Prior to beginning the coupled integration, the atmosphere model was run with observed SSTs for 3 years to reach its own climate and to spin up the soil model; the ocean model was run for $10000 \mathrm{y}$ driven by wind stress calculated from a 20-year integration with the atmosphere model to reach an equilibrium which is in balance with the wind field at the point of coupling. The coupled model has been run for $25 \mathrm{y}$ with normal $\mathrm{CO}_{2}$ concentrations and with instantaneously doubled $\mathrm{CO}_{2}$. In this contribution the results from the normal $\mathrm{CO}_{2}$ integration are shown.

\subsection{Multi-level AGCMs with low-resolution OGCMs}

\section{a) Meehl and Washington}

The atmospheric model has been used specifically for coupling to various ocean formulations (e.g., Washington and Meehl 1983, 1984, 1989; Meehl and Washington 1990). It is a global spectral GCM and includes rhomboidal 15 resolution (about $4.5^{\circ}$ longitude by $7.5^{\circ}$ latitude), 9 layers in the vertical, computed clouds, and parameterized land surface processes. Meehl and Washington (1988) have analyzed in detail the sensitivity of land surface processes in this model.

The ocean model has a coarse resolution $\left(5^{\circ}\right.$ latitude by $5^{\circ}$ longitude, four layers in the vertical) and includes realistic geography, bottom topography consistent with resolution, and a simple thermodynamic sea-ice formulation. Meehl et al. (1982) have tested this ocean model with a variety of parameter changes.

For the present experiment, the coarse-grid ocean model was first run by itself for 50 model years with observed atmospheric forcing. It was initialized the first year with observed vertical cross sections of temperature and salinity. The atmospheric model was also run separately for 15 model years, preceded by a spin-up period (Washington and Meehl 1984; Meehl and Washington 1985). Then both models were synchronously coupled and run for 16 model years. Following this shake-down period, the coupled model was run for $30 \mathrm{y}$ (Washington and Meehl 1989).

\subsection{Low vertical resolution AGCMs with low-resolution OGCMs}

\section{a) Gates, Han and Schlesinger}

The Oregon State University atmospheric GCM used here has a resolution of $4^{\circ}$ latitude and $5^{\circ}$ longitude, with two layers of equal mass in the vertical between the surface and $200 \mathrm{mb}$. Wind velocity, temperature, geopotential, and water vapor mixing ratio are calculated at the mid-points of the two atmospheric layers, i.e., at approximately 400 and $800 \mathrm{mb}$. Temperature, pressure, and moisture are also predicted as the sur- face. Cloudiness is internally calculated for convective and large-scale condensation processes, and local snow cover is simulated as part of the surface hydrologic balance. The solar radiative forcing varies both diurnally and seasonally. Further details of this model have been described in Schlesinger and Gates $(1980,1981)$ and Ghan et al. (1982).

The oceanic portion of the coupled model is basically the same as that described by Han $(1984 a, b)$. This is a 6-layer primitive-equation model of the world ocean with realistic lateral and bottom topography as resolved by the $4^{\circ}$ latitude and $5^{\circ}$ longitude grid. As distinct from the oceanic GCM described by Han $(1984 a, b)$, the model version used in the present coupled simulation has been extended to include the Arctic Ocean and includes a bulk sea-ice model.

The coupling of the atmospheric and oceanic portions of the model is straightforward: the net surface heat flux over the oceans serves as forcing for the determination of the ocean's surface and interior temperature, while the surface wind stress is similarly used for the calculation of the ocean currents. Oceanic salinity is found from a climatologically prescribed surface salinity, rather than from the simulated evaporation-precipitation difference. Atmospheric advection takes place every $10 \mathrm{~min}$, and the air temperature is updated once each hour as a result of diabatic heating; the surface (and interior) winds are updated hourly as a result of friction, which coincides with the basic one-hour time step of the ocean model. By such a synchronous exchange of heat and momentum at the sea surface both the ocean and atmosphere model are subject to full diurnal and seasonal forcing, and no time-smoothing or averaging is employed during the course of their simultaneous integration.

\section{b) Gates and Sperber}

The atmospheric component is the same as in Gates et al. (previous section). The ocean model developed by Pollard (1982) allows the interactive determination of the sea-surface temperature as well as the heat transport in the upper ocean. The ocean has two layers of variable depth crudely representing the mixed layer and the thermocline. The entrainment of water between the layers is parameterized according to the turbulent kinetic energy budget method of Niiler and Kraus (1977). The atmosphere and ocean exchange momentum and heat according to conventional bulk formulae, with both the mixed-layer temperature and thermocline temperature internally predicted. The model forms sea ice when the mixed-layer temperature falls below $-1.6^{\circ} \mathrm{C}$, while sea ice heat storage, leads, and dynamics are ignored. The salinity is prescribed, while the eddy diffusion of heat and momentum are parameterized with constant Laplacian diffusion coefficients.

Prior to coupling with the atmospheric model, the ocean model was spun-up from an initially static state with 16 months of observed wind stress forcing. The atmosphere and ocean were synchronously coupled with- 
out the application of flux-correction terms at the ocean surface and integrated for 15 years. Gates and Potter (1991 submitted to Climate Dynamics) report the basic performance of the model, as well as the climate change induced by a doubling of $\mathrm{CO}_{2}$. Aspects of the simulated surface pressure, temperature, precipitation, surface currents, and thermocline depth have been considered by Sperber (1989), while the model's simulation of the Southern Oscillation has been reported by Sperber et al. (1987), Sperber (1989), Hameed et al. (1989) and Sperber and Hameed (1991).

\subsection{Simple atmospheric models with high-resolution OGCMs (hybrid coupled models)}

\section{a) Neelin}

The atmospheric component of this hybrid coupled model is a steady-state two-layer model with moist processes and surface stress parameterized following Neelin and Held (1987) and Neelin (1988). The atmospheric dynamics represent the boundary-layer circulation which is heavily damped by vertical momentum transfer to the surface stress. The bulk effects of convection are represented as a near-balance of diabatic heating due to moisture convergence and adiabatic cooling due to rising motion, subject to the requirement that the circulation be thermodynamically direct. Boundary-layer moisture content is parmeterized on SST, and high moisture content is the primary factor in organizing convection over warm SST. The atmospheric response is qualitatively similar to a Gill (1980) model but with a nonlinear dependence on SST. The model parameters were chosen by comparing to the response of the AGCM of section 2.1a and the atmospheric model performance for ENSO conditions is presented in Neelin (1990).

The ocean model is a version of the ocean GCM described in section 2.1 a with slightly coarser resolution, having a mesh of $1^{\circ}$ latitude by $3^{\circ}$ longitude at the equator. The equation of state is also replaced by a linear dependence on temperature for tropical ocean studies. The active ocean domain is $130^{\circ} \mathrm{E}$ to $80^{\circ} \mathrm{W}$ and $30^{\circ} \mathrm{S}$ to $50^{\circ} \mathrm{N}$, with sponge layers restoring temperature toward climatology at high latitudes.

Coupling is carried out by 'one-way' flux correction: the ocean model is spun up in response to observed climatological wind stresses. The atmospheric model response to this ocean climatology is then found. At each coupling time step, the atmospheric model climatology is subtracted from the atmospheric model response and replaced by observed climatological wind stresses. The atmospheric model is thus effectively used as a nonlinear anomaly model. The climatology is a known stationary state of the system although it may be unstable. Annual average conditions are used. A coupling time step of 15 days is used, with oceanic conditions averaged over the previous period passed to the atmospheric model which returns the steady-state atmos- pheric response to these conditions. This choice is made because the assumptions of the atmospheric model would not be valid for the response to higher frequency fluctuations in boundary conditions. Further description may be found in Neelin $(1989,1990)$.

Three experiments are discussed here for different parameters and initial conditions. The atmospheric model is altered so as to produce a weaker or stronger anomalous wind stress response for a given oceanic configuration. The 'relative coupling coefficient' is defined to be the strength of the stress response relative to that for the best case parameters.

\section{b) Allaart, Jansen, Kattenberg and Verhaar}

The atmospheric model consists of two components: a linear atmospheric-dynamics model and a heating scheme. The atmospheric-dynamics component is the linear, global-domain, steady-state anomaly model described by Opsteegh and Mureau (1984) which gives the atmospheric response to a prescribed heating. A parameterization scheme for atmospheric heating above tropical oceans, based on a moisture budget equation, was developed by Jansen and Verhaar (1991; personal communication) to force the atmospheric model in the coupled experiments.

The ocean model is a primitive-equation, Cartesiancoordinate model with variable resolution. It is similar to the model by Latif and Maier-Reimer (Latif 1987) and it is described and documented by Allaart and Kattenberg (1990). Some aspects of its spin-up, in relation to the inclusion of salinity in the model, were described by Kattenberg and Allaart (1989).

Coupling is accomplished via 5 fields (SST, zonal and meridional stress, heat flux and fresh-water flux) which are communicated between the models on a $2^{\circ}$ latitude by $2^{\circ}$ longitude grid in the region bounded by $\pm 29^{\circ}$ latitude, $124^{\circ} \mathrm{E}$ and $70^{\circ} \mathrm{W}$ longitude, with realistic land-contours. The fields that are presented to the ocean component consist of anomalies that are produced by the atmosphere and heating components, supplemented with climatological values that were generated by the ocean model in an uncoupled control-experiment. During this control run, the ocean model was forced to equilibrium with Florida State University winds (Goldenberg and O'Brien 1981), Climate Analysis Center SST (Reynolds 1988) and the climatological surface salinity from the Levitus (1982) atlas.

The ocean model and the heating scheme/atmosphere model were developed separately (and uncoupled). For the ocean model no tuning was possible or necessary, while the atmospheric component was tuned during its development mainly to produce an optimal simulation of the precipitation climatology. The coupling was done 'as is', without any correction. The anomaly fields are coupled as follows: SST anomalies are passed to the heating scheme; heat and fresh water flux anomalies are passed from the heating scheme to the ocean; wind anomalies are passed from the atmospheric-dynamics component to the ocean. 


\subsection{Simple atmospheric models with low-vertical high-horizontal resolution OGCMs}

\section{a) Schopf and Suarez}

The atmosphere model is a $4^{\circ}$ latitude by $5^{\circ}$ longitude finite-difference model with two layers. It has no moisture nor clouds, and tends to respond to SST anomalies very much like the simple linear dynamics of Gill (1980). It does, however, have nonlinear dynamics that are primarily expressed in midlatitude instabilities and eddies that influence the tropics in a nondeterministic manner.

The ocean model is a "two-and-one-half" layer model, solving primitive equation nonlinear dynamics in two layers above a quiescent abyss (Schopf and Cane 1983). The uppermost layer is a bulk mixed layer, employing a variant of the Kraus-Turner mixed-layer dynamics to determine its thickness. The second layer has a quasi-material property, with a mean depth of about $150 \mathrm{~m}$. Resolution is regular in latitude and longitude, at $\frac{2}{3} \circ$ by $1.25^{\circ}$ spacing throughout the Pacific basin, with a domain from $120^{\circ} \mathrm{E}$ to $80^{\circ} \mathrm{W}$ and $20^{\circ} \mathrm{S}$ to $20^{\circ} \mathrm{N}$. Although the mixed-layer equations are solved everywhere for determining entrainment and detrainment, along the equator the vertical advection term dominates the solution. In the east, strong upwelling thins the layer to a numerically based minimum criterion, while in the west, the accumulation of mass in the surface layer leads to a relatively deep mixed layer, which is also capped at a pre-set limit. A key parameter in the simulations was the thickness of the lower layer. When this layer becomes too shallow, water is brought up from below.

Coupling is synchronous, with the surface heat flux simply proportional to the air-sea temperature difference. Because the atmospheric model does not carry moisture, no distinction is made between sensible and latent heat. The atmospheric surface temperature is strongly constrained because the atmospheric temperature structure is relaxed toward a prescribed profile which is a function of latitude only, symmetric about the equator. The wind stress is proportional to lower level wind and is passed to the ocean without flux correction.

In an additional integration, the atmosphere was replaced with a version linearized about a state of rest, with heating proportional to SST anomalies and prescribed mean wind stress taken from the original coupled run. Further details of the models are given in Schopf and Suarez (1988).

Recently a new Schopf and Suarez model has been developed, also based on nonlinear reduced gravity equations, but with 7 layers extending down to $3000 \mathrm{~m}$. Horizontal resolution is as in the old model, but the domain is global. Initial tests have been done coupling the ocean with an eight-layer AGCM with a $4^{\circ}$ by $5^{\circ}$ grid and including interactive clouds. A preliminary description of this model's behavior is included at the end of section 3.6a.

\section{b) Zebiak and Cane}

Both the atmospheric and oceanic components of the model describe perturbations about the mean climatological state, with the monthly climatology specified from observations (Rasmusson and Carpenter 1982). The atmospheric model is that of Zebiak (1986). The atmospheric dynamics take the form of the steady, linear shallow-water equations on an equatorial betaplane. The circulation is forced by a heating anomaly which depends partly on local heating associated with SST anomalies and partly on the low-level moisture convergence. The latter effect is nonlinear because latent heating occurs only when the total wind field is convergent, and this is a function of the background mean convergence as well as the calculated anomalous convergence. The latent heating feedback tends to focus the atmospheric response to SST anomalies into or near the regions of mean convergence.

The model ocean basin is rectangular, and extends from $124^{\circ} \mathrm{E}$ to $80^{\circ} \mathrm{W}$, and $29^{\circ} \mathrm{N}$ to $29^{\circ} \mathrm{S}$. The dynamics of the model begin with the time-dependent shallow-water equations. The currents produced by these dynamics alone represent depth-averaged baroclinic currents. A frictional surface layer of $50 \mathrm{~m}$ depth is added to simulate the near-suface intensification of winddriven currents. The thermodynamics describe the evolution of temperature anomalies in the model surface layer. All terms, including nonlinear advection components, are retained. Temperature anomalies below the base of the surface layer are parameterized in terms of vertical displacements of the model thermocline (identified with movements of the layer interface). The ocean model and coupling scheme are described in Zebiak and Cane (1987).

\section{Results}

\subsection{Multi-level AGCMs with high-resolution OGCMs}

\section{a) Philander, Lau and Pacanowski}

At the beginning of the integration, horizontal pressure gradients in the ocean are not in balance with the atmospheric model wind stress, which is spinning up from rest. As a result, a warming similar to an El Niño develops in the first year. An irregular oscillation between warm and cold conditions occurs thereafter (Fig. 2). There is little trend in SST or other model variables over the course of the run. Although the surface wind stress simulated by the atmospheric model is about $30 \%$ to $40 \%$ weaker than the estimates of Hellerman and Rosenstein (1983) and equatorial currents are weaker than observed, the SST pattern in the tropical Pacific is quite similar to observed. In particular, the cold tongue and warm pool are in the correct positions and have approximately the correct magnitudes compared to annually averaged observations.

On long interannual time scales, SST anomalies tend to develop in place, although there is some tendency 


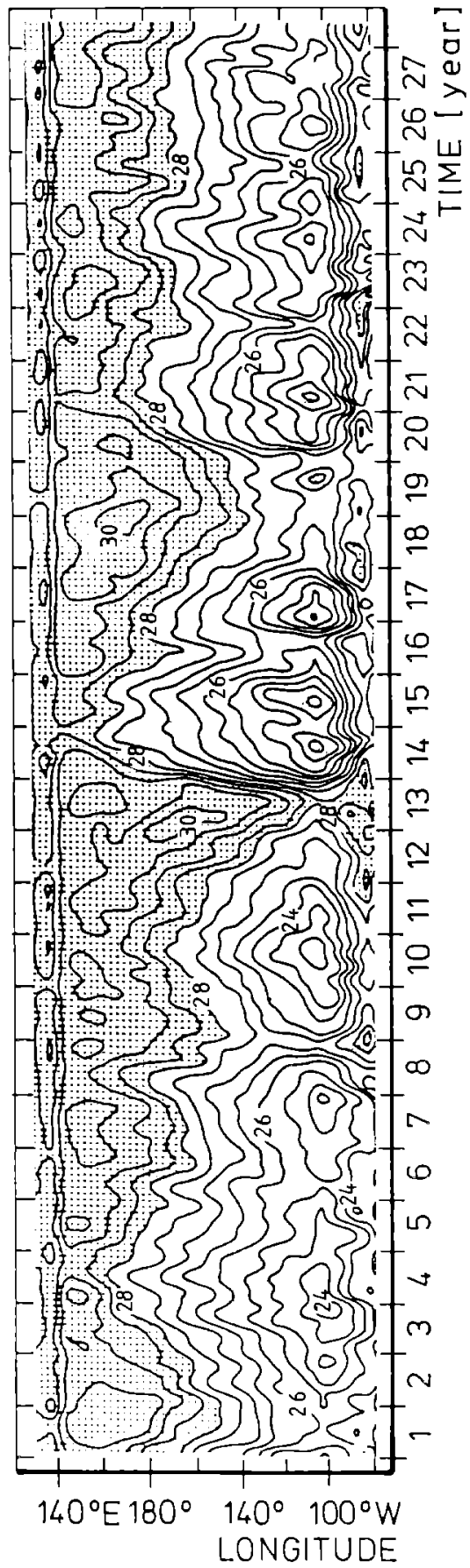

Fig. 2. Pacific SST along the equator over 28 years of simulation (without seasonal cycle) by the coupled model of Philander et al. (section 3.1a). Smoothing by a 13-month running mean has been applied. Contour interval $0.5^{\circ} \mathrm{C}$, shaded over $28^{\circ} \mathrm{C}$

for eastward propagation prior to the onset of the warm phase and possibly westward prior to the cold phase. The interval between warm and cold phases is irregular so it is difficult to specify a dominant period, but the characteristic length of a major warm or cold event is on the order of three years. Amplitudes of interannual warm or cold anomalies are realistic compared to observed ENSO events. The maximum SST anomaly tends to be located between $120^{\circ}-140^{\circ} \mathrm{W}$, further west than the canonical Rasmusson and Carpenter (1982) composite, but the structure of warm and cold phases is comparable to observed. A more detailed analysis is given in Philander et al. (1992). Wind anomalies occur in temporal phase with the SST anomalies. An important feature to the oscillation is a very slow eastward propagation of high (low) equatorial heat content anomalies, which occurs in the west Pacific over one or more years preceding the onset of a warm (cold) phase. The subsurface "memory" associated with these heat content anomalies appears important to the oscillation. However, it appears to be the signature of a slowly evolving coupled mode, rather than individual free oceanic Rossby and Kelvin wave modes.

In addition to the interannual variability on time scales on the order of 6 years, substantial variability is to be found in the SST field at a period of roughly 7 months. This appears to be associated with a quasiresonant oceanic mode. A running time average has been used to remove this effect from Fig. 2 to allow the long time scale variations to be more clearly seen.

Two test runs have also been carried out with a version of the atmospheric model that includes interactive cloud cover which affects the radiative transfer. While these results are too preliminary to draw firm conclusions, it is clear that the model showed considerable sensitivity to this change in parameterization.

\section{b) Gordon and Ineson}

The older version of the model (Run-1; no Fig. shown) was integrated for 2.5 years. While this is not sufficiently long to establish a climatology, systematic errors could be seen in the seasonal cycle each year. This state exhibits many of the features of a major ENSO event. The warm pool is displaced eastward of its climatological position, and the Trades have collapsed in the western Pacific. Although the ocean model had been spun up for 4 years with AGCM wind stresses to minimize the initial imbalance between the two components, the model migrated to this state early in the run on a time scale of months. Further description may be found in Gordon (1989b).

The new version of the model (Run-2) has been integrated for 13 years and the equatorial (mean for $5^{\circ} \mathrm{N}$ to $5^{\circ}$ S) SSTs are shown in Fig. 3. A number of features are immediately evident. There is a climate drift in the model leading to a cooling of the Pacific. Near the start of the simulation the model is too warm compared to climatology with the $28^{\circ} \mathrm{C}$ water extending east of $160^{\circ} \mathrm{W}$. By year 8 the warm pool is essentially in its climatological position and after this time the warm pool retreats towards the west. It is clear from Fig. 3 that there is a well-defined seasonal cycle in the model. It is however too weak in the east Pacific and this can be traced to the Trades being too weak around September (when the cold tongue should be at its maximum extent). This is a rather interesting feature since the Trades are not too weak in the control atmospheric integration with climatological SSTs. The Trades do pick 


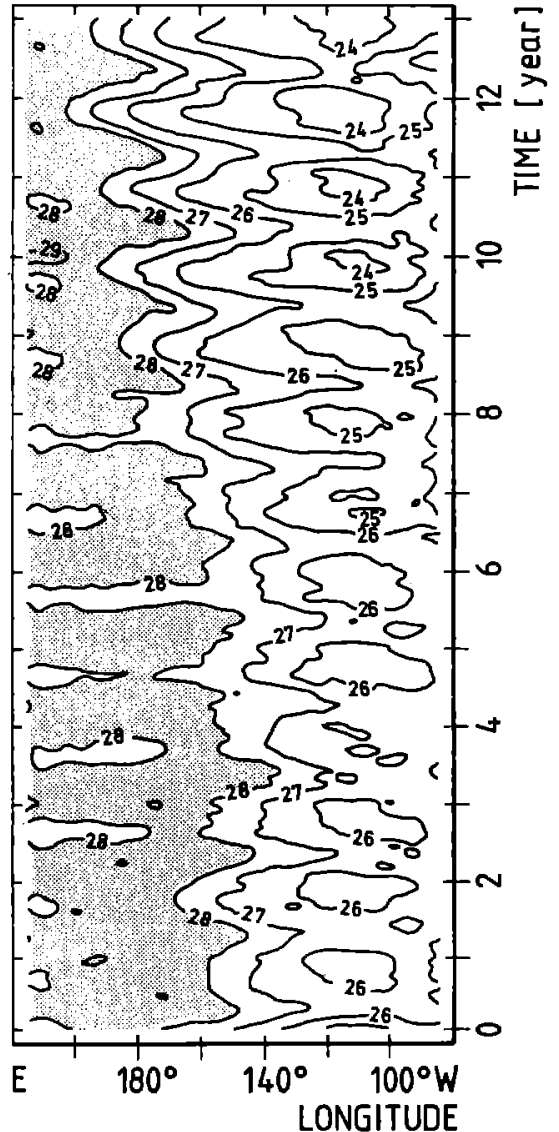

Fig. 3. Pacific SST averaged from $5^{\circ} \mathrm{S}$ to $5^{\circ} \mathrm{N}$ over 13 years of simulation by Gordon and Ineson (section 3.1b). Contour interval $1^{\circ} \mathrm{C}$, shaded over $28^{\circ} \mathrm{C}$

up later in the simulation and this is reflected in the larger seasonal variation of SSTs in the equatorial $\mathrm{Pa}$ cific. Overall, the climate drift is greatly reduced in this version of the model, with climatology and seasonal cycle qualitatively similar to observed.

An unfortunate feature of the integration is the lack of interannual variability in the east Pacific with a signature similar to El Niño. Although there is some variability it is very weak - indeed, the main interannual signal in the model is not on the equator but is situated under the South Pacific Convergence Zone south of the equator. It seems unlikely that the initial warming and subsequent cooling are part of an oscillation unless it is of very long period. All of these model features are still under investigation.

\section{c) Latif, Biercamp, von Storch and Zwiers}

The most obvious result of the ten year integration is its climate trend (Fig. 4). The entire equatorial ocean experiences a continuous cooling which is connected with atmospheric anomalies somewhat analogous to the Southern Oscillation during a cold event. The ocean cools more quickly during the first two years of the integration than during the subsequent 8 years. During the last 8 years the trend has almost constant slope. In

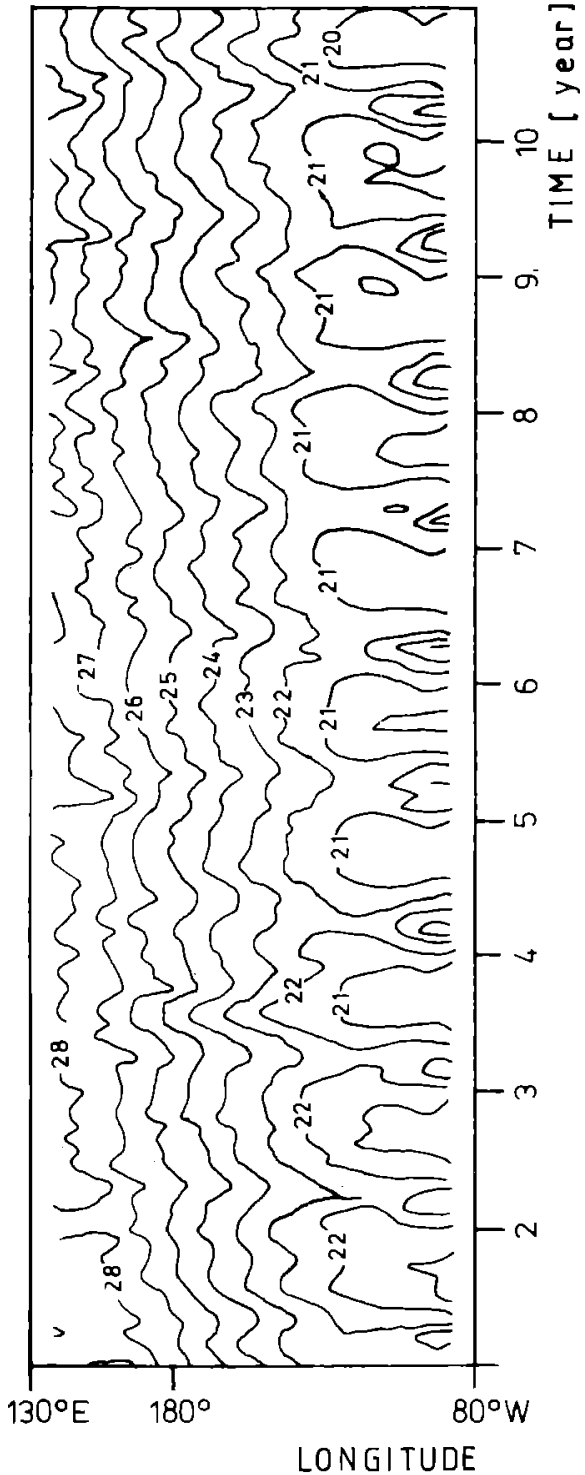

Fig. 4. Pacific SST along the equator over 10 years of simulation by Latif et al. (section 3.1c). Contour interval $1^{\circ} \mathrm{C}$

contrast to the equatorial region there is a tendency for a slight increase in SST at higher latitudes.

A similar decrease in SST within the narrow equatorial belt was seen in a 10-year integration with the ocean model run in an uncoupled mode forced by climatological wind stress and a heat flux determined from the last seasonal cycle of the spin up integration. Therefore, the trend observed in SST simulated in the coupled run may be attributed primarily to the ocean model which, due to its closed basin, does not contain the processes which are necessary to maintain the thermocline. Consequently the initial stratification of the ocean is gradually destroyed by explicit and numerical heat diffusion, leading to a cooling of the upper layers and a warming in the deep ocean.

The cooling of the Equatorial Pacific Ocean's surface is reflected in atmospheric quantities such as sea level pressure (SLP), rainfall, $850 \mathrm{hPa}$ temperature and $300 \mathrm{hPa}$ velocity potential. Locally, i.e., in the vicinity 
of the cooled ocean's surface, the atmosphere reacts with strongly decreased rainfall and decreased temperatures. Maximum precipitation deficits occur slightly to the west of the dateline with values of about $7 \mathrm{~mm} /$ day. Maximum cooling at the $850 \mathrm{hPa}$ level, for instance, amounts to about $0.3^{\circ} \mathrm{C}$ near the dateline.

It is not surprising that there are also remote changes in the atmospheric state which correspond to the strong changes in local circulation described above. In particular SLP is reduced by as much as $2 \mathrm{hPa}$ in the tropics outside the Pacific Ocean where no surface cooling takes place and excess rainfall of up to $4 \mathrm{~mm}$ / day is found over the Indian Ocean. There are increased $850 \mathrm{hPa}$ temperatures with maximum values of $0.3^{\circ}$ to $0.6^{\circ} \mathrm{C}$ over the Indian ocean. SLP also shows a remote response in the North Pacific sector. This SLP response, which is reminiscent of the negative Pacific/ North-American pattern (PNA), appears most strongly in winter and is absent in summer. This is in full accord with a finding of Barnston and Livezey (1987), who identified the PNA as an anomaly pattern which is excited in all seasons except northern summer. These remote differences are also reminiscent of anomalies found by Cubasch (1985) when forcing the uncoupled atmospheric model with a negative SST anomaly in the Equatorial Pacific.

As can be further seen from Fig. 4, the interannual variability is weak. In particular, no eastward excursions or westward retreats of the warm surface waters occur in the Central Pacific as is typical for this region. The standard deviation of monthly mean SST anomalies on the equator is only of the order of a few tenths of a degree.

\section{d) Latif and Sterl}

Initially the coupled model undergoes a rapid adjustment process in response to a relaxation of the trade winds resulting in anomalously warm surface water during the first two years, as shown in Fig. 5. Thereafter, the coupled model undergoes an annual cycle with westward phase propagation in SST. Superimposed is a slight cooling trend and considerable low-frequency variability. In the far eastern Pacific, rather high SSTs are simulated with values up to $30^{\circ} \mathrm{C}$.

Interannual variability in SST is dominated by a standing component. The anomalies are centered in the eastern Pacific near $115^{\circ} \mathrm{W}$ and attain maximum values of about $3^{\circ} \mathrm{C}$ in the center of action. A preliminary investigation of the results revealed the importance of equatorial waves for the simulated interannual variability. Upper ocean heat content anomalies show a pronounced westward phase propagation off the equator and eastward propagation on the equator. However, the slow phase speeds indicate that different wave modes rather than one single mode are of importance. As for the SST, the zonal wind stress anomalies are dominated by a standing component with maxima in the central Pacific to the west of the maximum SST anomalies. In sum, these results are indicative of a modified "de-

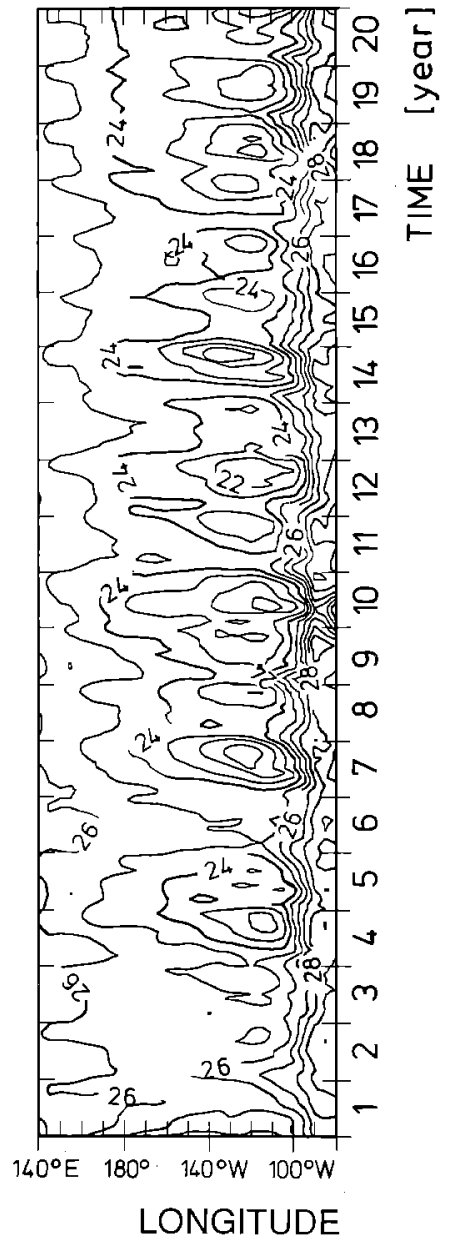

Fig. 5. Pacific SST along the equator over 20 years of simulation by Latif and Sterl (section 3.1d). Smoothing by a 7-month running mean has been applied. Contour interval $1^{\circ} \mathrm{C}$

layed-action oscillator" as the basic mechanism for the interannual variability in this model.

The fact that this version of the coupled model oscillates while the earlier version did not is interesting. Although many changes have been made in the ocean model, it is reasonable to speculate that the removal of the flux correction is the main reason for the different coupled behaviors. Adding easterlies in the flux-corrected run results in increased mean vertical velocity in the ocean due to a strengthening of Ekman divergence. It is known from stability analysis that the mean upwelling acts as a negative feedback on SST anomalies. The flux correction might therefore act to stabilize the coupled system.

\section{e) Gent and Tribbia}

The coupled model was initially run for a year in annual average mode. Adjustments in the values of two surface parameters and in the ocean longitude resolution were made. The first coupled calculation with annual cycle has now been run out for 11 years. Sea surface temperature along the equator is shown in Fig. 6. 


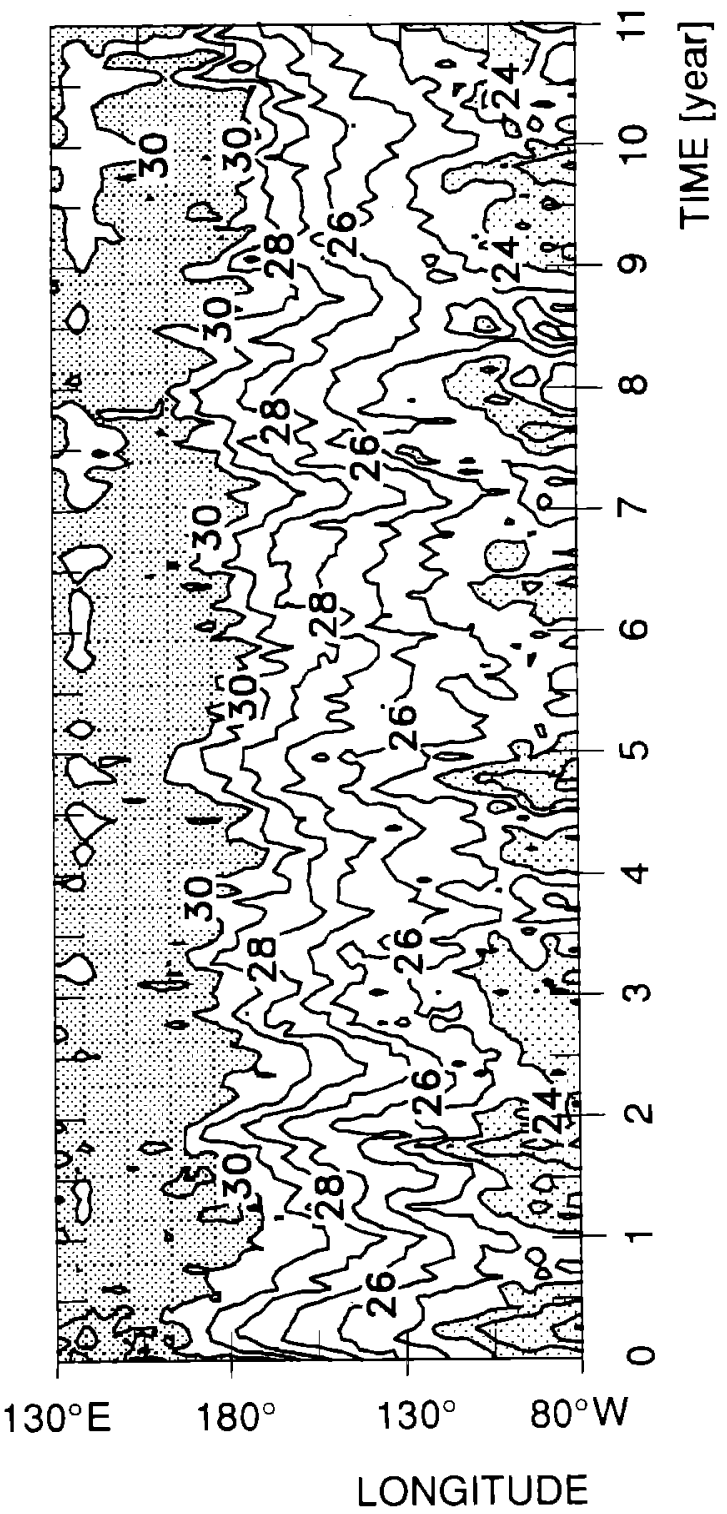

Fig. 6. Pacific SST along the equator over 11 years of simulation by Gent and Tribbia (section 3.1e). Contour interval $1^{\circ} \mathrm{C}$, shaded over $30^{\circ} \mathrm{C}$ and under $24^{\circ} \mathrm{C}$

The gross features of the Indonesian warm pool and the equatorial cold tongue are well reproduced although the SST is slightly warmer than observed. The model is close to symmetric about the equator but nonetheless the general features of the seasonal movements of the cold tongue are in qualitative agreement with observations. Climate drift over the course of the run is quite modest. The warm pool cools slightly, especially near the western coast but the tendency for the warm pool to detach from the coast is not severe. The coldest water is almost always found near the eastern coast, in contrast to many of the other models. There is a tendency for the cold tongue to be warmer during the latter part of the run compared to the earlier part.

There is considerable interannual variability over the course of the run, with anomalies of greater than $1^{\circ} \mathrm{C}$ occurring aperiodically. The run has not yet been sufficiently analyzed to determine the exact nature of this variance but anomalies appear to develop more in place than to show clear propagation.

\section{f) Mechoso, Ghil, Halpern, Fisher and Spahr}

Two preliminary runs with the coupled model are described here. Initial conditions for the AGCM are taken from previous climatological runs with prescribed observed boundary conditions. The OGCM is started from rest with observed stratification specified from the Levitus (1983) climatology. The first run (Run-1; not shown) has the seasonal cycle of insolation and was run for four years. SSTs tend to be too warm both along the equator, particularly in the central part of the basin, and in the subtropics, particularly in the summer hemisphere, with considerable areas of water warmer than $30^{\circ} \mathrm{C}$. The warm-pool/cold-tongue structure, which is well modeled in the uncoupled OGCM and is present in the initial conditions, collapses within the first few months of the run, in a manner reminiscent of the onset of a major El Niño. A seasonal cold tongue near the eastern part of the basin re-establishes itself during the second year of the run, but does not reach the intensity of the observed cold tongue. The last three years of the run seem to establish an equilibrium climatology in which the warm pool occurs in the central part of the basin with colder water near the western coast in the Indonesian region. The processes responsible for maintaining this state appear to involve a coupled feedback between surface fluxes, vertical mixing in the ocean, SST and winds.

The departure from realistic behavior has been traced to the interaction between the vertical-mixing and long-wave radiation parameterizations in the OGCM and AGCM, respectively. When surface fluxes are large, the warming of the upper layers tends to increase the stability of these layers. The Richardsonnumber-dependent mixing scheme used here is extremely sensitive to this and tends to shut off the vertical mixing, resulting in an overly-shallow, warm mixed layer. An interesting consequence of this is that the Intertropical Convergence Zone (ITCZ) in the Pacific tends to migrate between hemispheres with season.

To gain insight into these issues, uncoupled OGCM tests were conducted, first, with wind stress and air temperature specified from observations, and, second, using AGCM wind stress and prescribing observed SSTs, the implied surface flux being diagnosed for comparison to observations. These tests and previous diagnostic studies with the AGCM did not immediately reveal anything obviously wrong with either the mixing or heat flux parameterizations. With the benefit of hindsight, we note that the maximum surface heat flux diagnosed from the OGCM in the substropics of both hemispheres is about half the observational estimates and occurs in spring not in summer as observed, while the seasonal cycle of heat flux in the uncoupled AGCM is generally comparable to observational estimates and has the correct seasonal phase. 


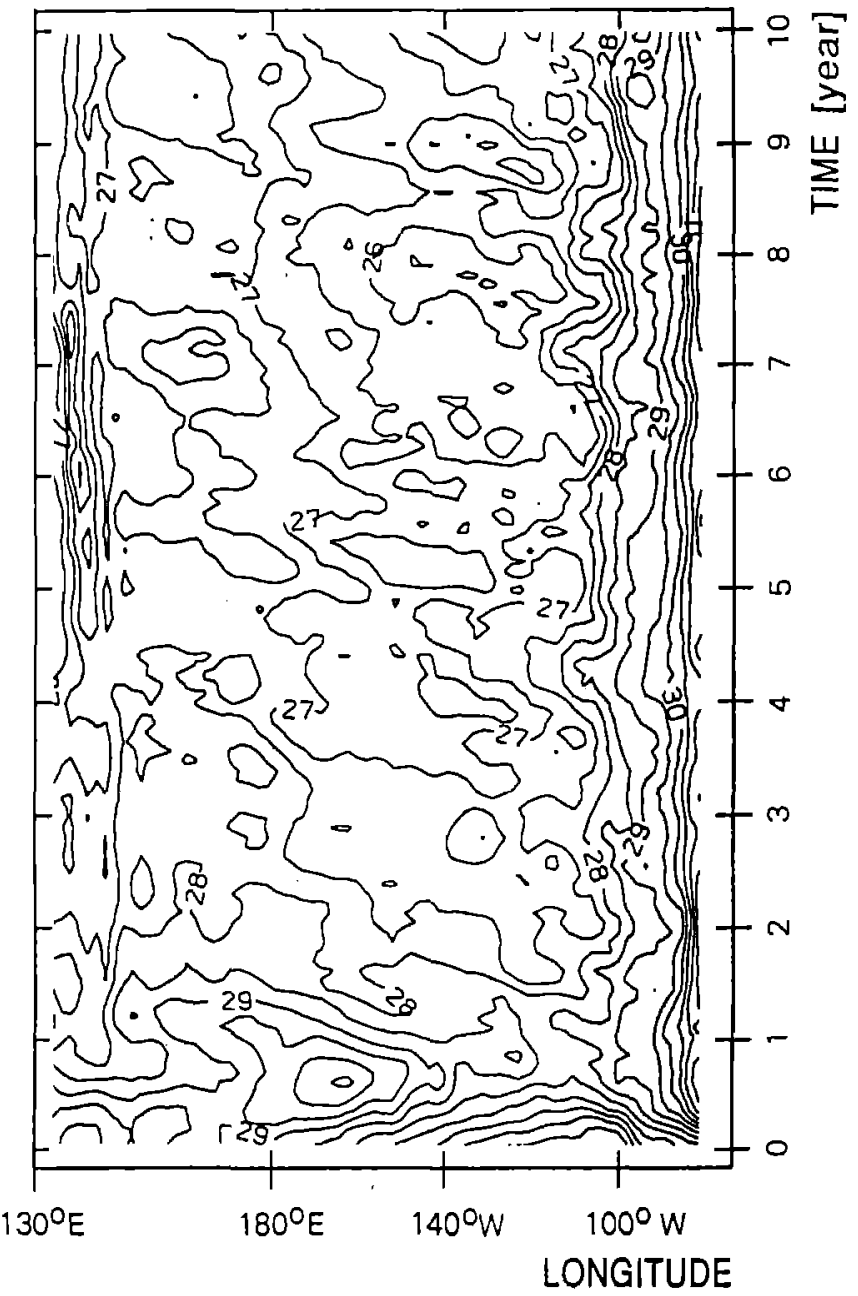

Fig. 7. Pacific SST along the equator over 10 years of simulation (in perpetual January mode) by Mechoso et al. (section 3.1f). Smoothing by a 5 -month running mean has been applied. Contour interval $0.5^{\circ} \mathrm{C}$

The migration of the ITCZ into the Southern Hemisphere in the previous run raises the question of how the system behaves under conditions in which the ITCZ is permanently in the Southern Hemisphere. A second integration (Run-2) was carried out in which the model was run in perpetual January mode for ten years. The behavior of the equatorial SST may be seen in Fig. 7. After an initial warm event, the cold tongue re-establishes itself in the east-central Pacific, although it is weaker than the observed climatology. It is maintained by north-easterlies, which cross the equator toward the Southern Hemisphere ITCZ in roughly the converse configuration to the pattern associated with the normal Northern Hemisphere ITCZ. A small region of warm water appears at the eastern coast and the western $\mathrm{Pa}$ cific does have relatively warm water although not quite as warm as observed. Although the temperature gradient across the basin is weak, the model nonetheless has interannual variability. SST anomalies of up to $1^{\circ} \mathrm{C}$ appear in some years and propagate slowly westward across the basin, as may be seen more clearly in anomaly plots (not shown).
More recently an integration has been begun using the Harshvardhan et al. (1987) radiation calculation, a Mellor-Yamada-type vertical-mixing scheme, and allowing short-wave radiation to penetrate beyond the OGCM upper layer, as in Rosati and Miyakoda (1988). Preliminary results indicate a much more realistic simulation of maximum SST and subtropical SST than is presented here. The several years of integration analyzed so far show a well-established cold tongue and warm pool in the correct locations and exhibiting a very reasonable seasonal cycle.

\subsection{Multi-level AGCMs with low-horizontal high-vertical resolution OGCMs}

\section{a) Lau, Philander and Nath}

The evolution of SST averaged between $2.25^{\circ} \mathrm{N}$ and $2.25^{\circ} \mathrm{S}$ for a twenty year segment of the model run is shown in Fig. 8. The values have been smoothed by a 3-month running mean. No prominent trend is evident in model fields over the 140 years of the run. Long term average climatology of SST is reasonably realistic, with both warm pool and cold tongue reproduced in approximately the observed locations. The cold tongue is not as strong as observed, associated with weak equatorial upwelling. The pattern of wind stress is in agreement but the magnitudes are less than half the observed annual average.

Interannual events occur with a time scale of 3 to 4 years. Spectral analysis indicates that SST variability has peaks at 33-40 months and at $66-80$ months. The segment shown represents a period of the model run when these events are fairly active; some other periods show less activity. The amplitudes of SST anomalies during these events range between $0.5^{\circ} \mathrm{C}$ and $1{ }^{\circ} \mathrm{C}$, which is weaker than observed.

SST events typically initiate in the eastern Pacific and migrate westward with time. The average time elapsed between the appearance of the signal in the east and its arrival in the west Pacific is 12-15 months. SST anomalies attain their highest amplitudes in the central part of the basin. Associated anomalies occur in zonal wind stress, sea level pressure, precipitation, surface currents and ocean heat content; warm events are associated with weakened Trades and zonal sea level pressure gradients and with enhancement of rainfall near the date line and of eastern Pacific heat content; during cold events the reverse occurs. Extended empirical orthogonal function (EOF) analysis indicates westward migration in these fields in accord with the westward migration visible in the SST field. A number of different advection terms of the surface heat budget contribute to the time tendency of SST at various phases of its evolution. These are described in greater detail in Lau et al. (1992). 


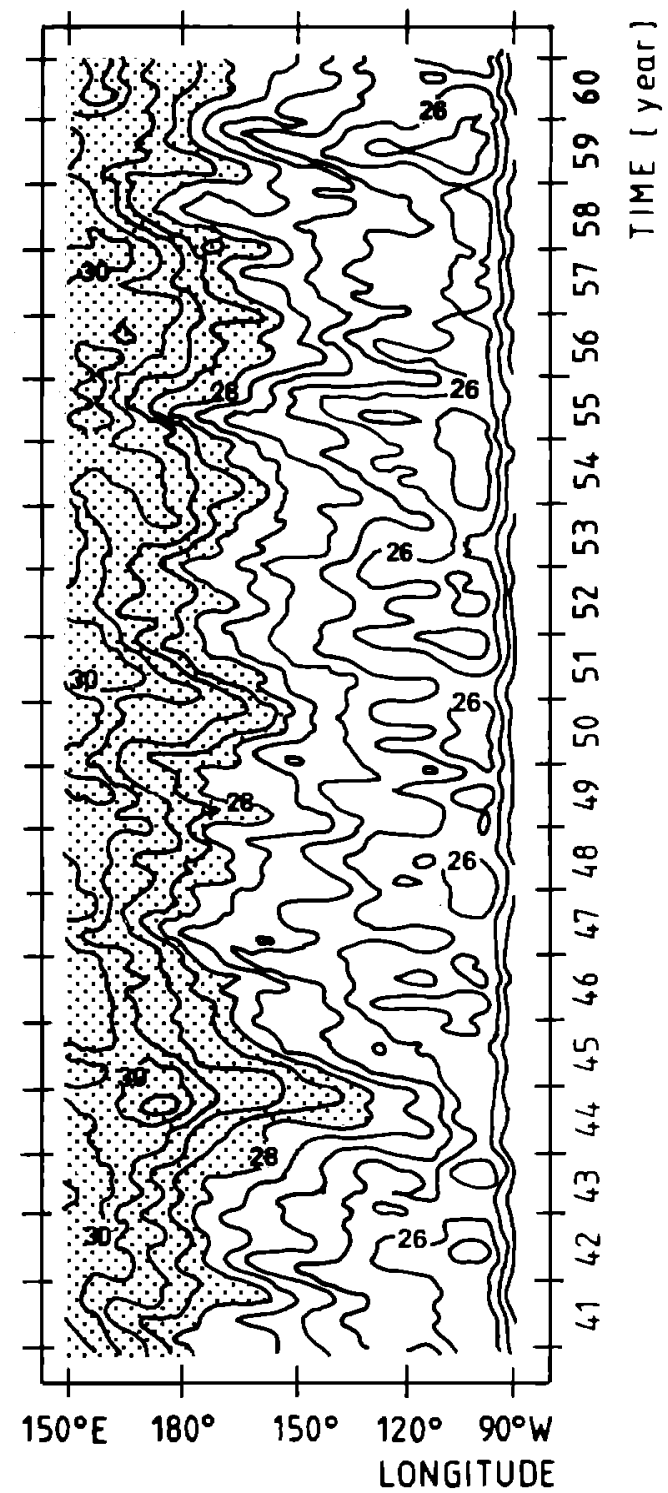

Fig. 8. Pacific SST averaged from $2.25^{\circ} \mathrm{S}$ to $2.25^{\circ} \mathrm{N}$ over 20 years of simulation (without seasonal cycle) by Lau et al. (section 3.2a). Smoothing by a 3-month running mean has been applied. Contour interval $0.5^{\circ} \mathrm{C}$, shaded over $28^{\circ} \mathrm{C}$

\section{b) Tokioka, Endoh and Nagai}

Eight years of coupled integration are shown in Fig. 9. Results for the first month of the run (December of year 0) are not shown. SST in the western equatorial Pacific shows a cooling trend which is most pronounced during the first few years. The cool SSTs in the western Pacific may be in part affected by the prescription of SST in the Indian Ocean. Once SST decreases in the western Pacific, the temperature gradient between Indian Ocean and western Pacific increases, resulting in stronger easterlies and stronger upwelling, which favors still cooler SST in the western Pacific. SST in the east warms rapidly during the first year and is fairly steady thereafter.

Eastern Pacific SST shows a pronounced annual cycle which propagates westward, consistent with the ob-

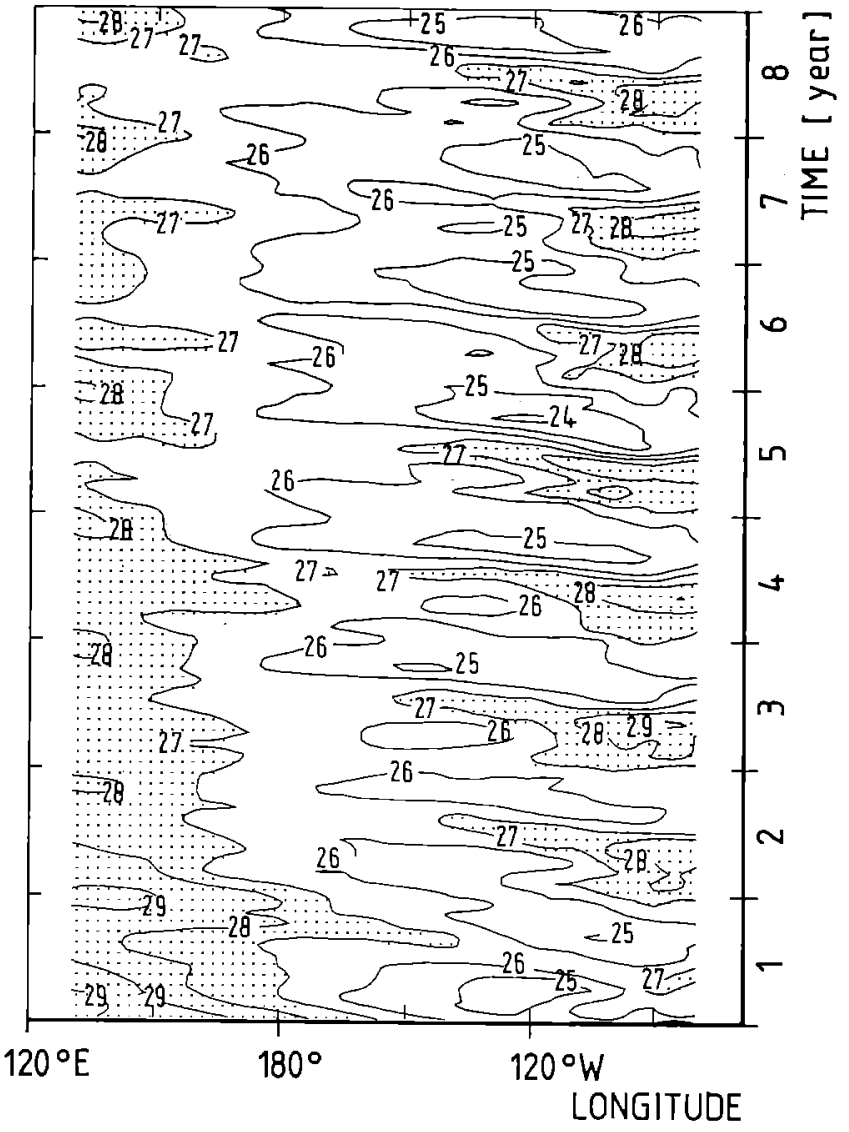

Fig. 9. Pacific SST averaged from $2^{\circ} \mathrm{S}$ to $2^{\circ} \mathrm{N}$ over 8 years of simulation by Tokioka et al. (section 3.2b). Smoothing by a 3month running mean has been applied. Contour interval $1^{\circ} \mathrm{C}$, shaded over $27^{\circ} \mathrm{C}$

servations of Horel (1982). The phase of the simulated annual cycle is slightly delayed relative to the observed annual cycle. Interannual variability is weak with low frequency anomalies on the order of $1^{\circ} \mathrm{C}$. Slow westward propagation may be found in the SST anomalies, qualitatively similar to that found by Lau et al. and Meehl and Washington.

Ongoing work with a version of the model with a high-resolution OGCM component shows more pronounced interannual variability. SST anomalies tend to develop more in place in the eastern Pacific, although still with some tendency towards westward propagation during parts of the cycle, and wave dynamics appears to be important to producing this variability. These results will be reported in detail elsewhere (Nagai et al. 1991, personal communication).

\section{c) Oberhuber, Lunkeit and Sausen}

Atmospheric, oceanic and ice initial conditions for the coupled run are taken from the end of the reference runs. In the integration without flux correction (Run-1; no Fig. shown), the model adjusts rapidly, within the first year, to a state in which no cold tongue appears in the eastern equatorial Pacific. This condition then per- 


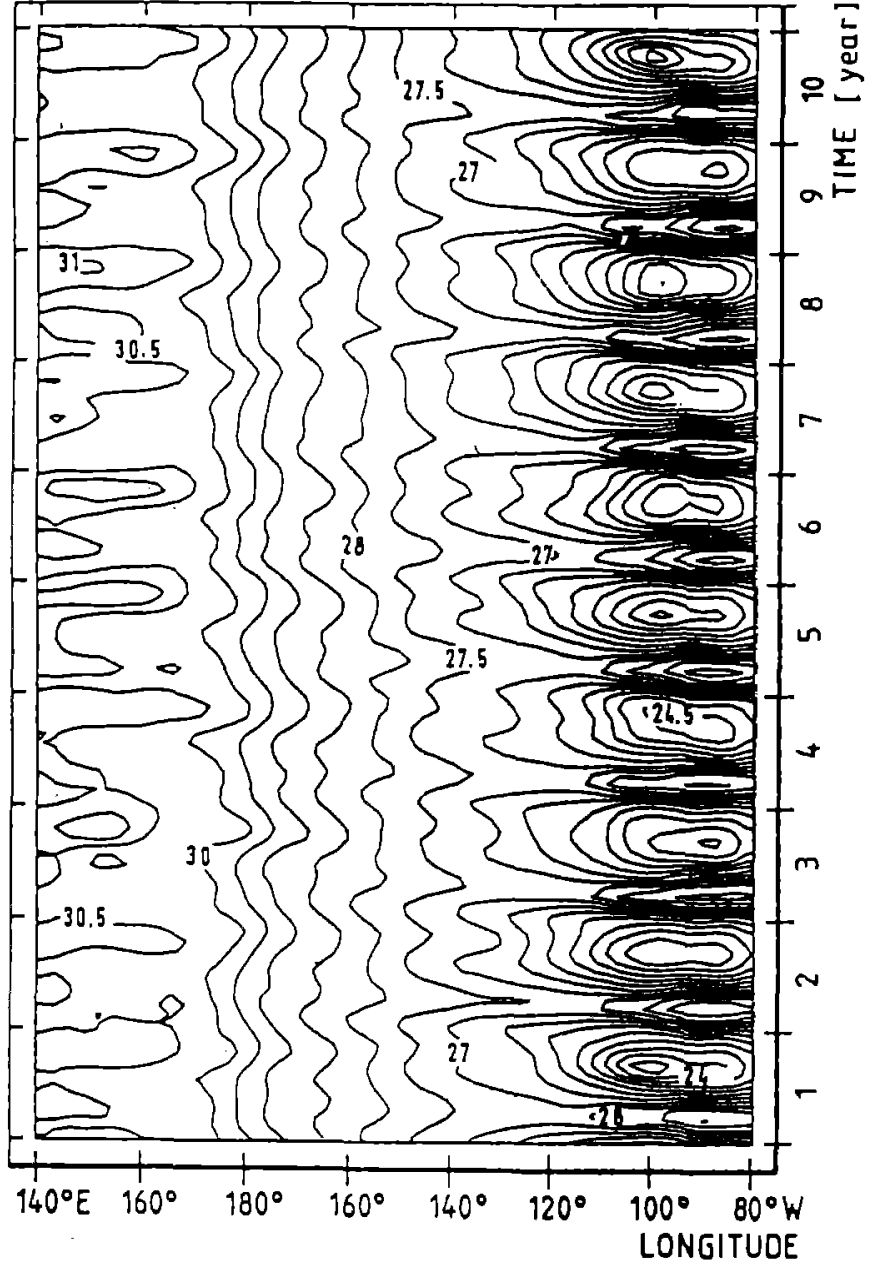

Fig. 10. Pacific SST along the equator over 10 years of simulation by Oberhuber et al. (section $3.2 \mathrm{c}$ ). Contour interval $0.5^{\circ} \mathrm{C}$

sists during the twenty-five years of the integration. This may be attributed to weak wind stresses from the AGCM. In response to observed SST, the AGCM gives Trade winds $30 \%$ weaker than observed. This results in a reduction of equatorial upwelling, which in turn tends to weaken the equatorial Trades in the coupled integration. Due to the weaker than observed meridional wind stress curl, boundary currents such as the Kuroshio and the Gulf Stream transport less heat into higher latitudes and the final SST patterns become too zonal.

For the integration in which flux correction is used (Run-2), SST evolution along the equator is shown in Fig. 10. The coupled model shows a weak trend towards a higher SST in the East Pacific. After 10 years of integration, the coupled model seems to arrive at a rather cyclo-stationary state. No El Niño-like oscillations appear in the SST fields. Only small fluctuations occur, with maximum values of about $0.5^{\circ} \mathrm{C}$.

There are several possible reasons for the absence of El Niño-like fluctuations. First, it might be a conceptual problem of the flux correction method. The atmospheric model underestimates the surface wind stress for anomalies as well as for the climatology. While the climatological stress is corrected, the anomalous stresses feeding back to the ocean are not. As a result, the relative magnitude of anomalous versus climatological stress is distorted.

A second reason for the missing fluctuations in the SST field might be the low meridional resolution both of the ocean model and of the atmosphere model, high spatial resolution having been forfeited because of the multidecadal integration times required for greenhouse gas scenario runs. The low meridional resolution in the ocean does not properly resolve equatorial waves while the atmosphere model with $5.6^{\circ} \times 5.6^{\circ}$ resolution does not respond sufficiently to anomalies in the narrow equatorial cold tongue. Both deficiencies might reduce the positive feedback between the SST field and the Walker circulation.

Although both components do not satisfactorily resolve some dynamical features which are believed to be important for the El Niño phenomenon, analysis of other fields such as surface currents and atmospheric convection indicates sufficient variability in the West Pacific. During the 10-year run, there occur several situations which look like the initial stages of an El Niño. Strong eastward currents west of the dateline appear and these have their counterpart in an eastward shift of the convection areas. From this it appears that the atmosphere model is able to produce stochastic perturbations which might be conductive to El Niño events but that the coupled feedbacks are not sufficiently strong for events to develop or for a cycle to be maintained.

\section{d) Cubasch and Böttinger}

Although the ocean model is able to produce a reasonable equatorial cold tongue when forced by atmospheric model winds, SST in the eastern Pacific region increases quickly over the first year of the coupled integration, as may be seen in Fig. 11. Thereafter, the zonal gradient across the Pacific remains weak relative to observations and to the uncoupled run. SST in the western Pacific is about $1^{\circ} \mathrm{C}$ cooler than observed in both coupled and uncoupled cases. Because of the lack of pronounced zonal gradients or cold tongue, the seasonal cycle of SST on the equator is very weak, being apparent mainly in the western Pacific and the very eastern margin of the basin.

Interannual variability is weak with no event resembling a major El Niño found in any integration. Perturbations resembling onsets appear but vanish without growing into a full El Niño. The same is true for cold events which seem to develop more strongly, but never persist. The 'large scale geostrophic' model avoids the equator, because it is not defined there. Its dynamics would prevent interannual oscillations due to wave feedback mechanisms, although feedbacks involving upwelling induced by Ekman pumping would be possible. Alternately, the feedback between SST and the atmosphere model might not be strong enough to maintain an El Niño. This could arise due to the low resolution or the choice of parameterizations, or possibly the stratification of the model atmosphere, which is too sta- 


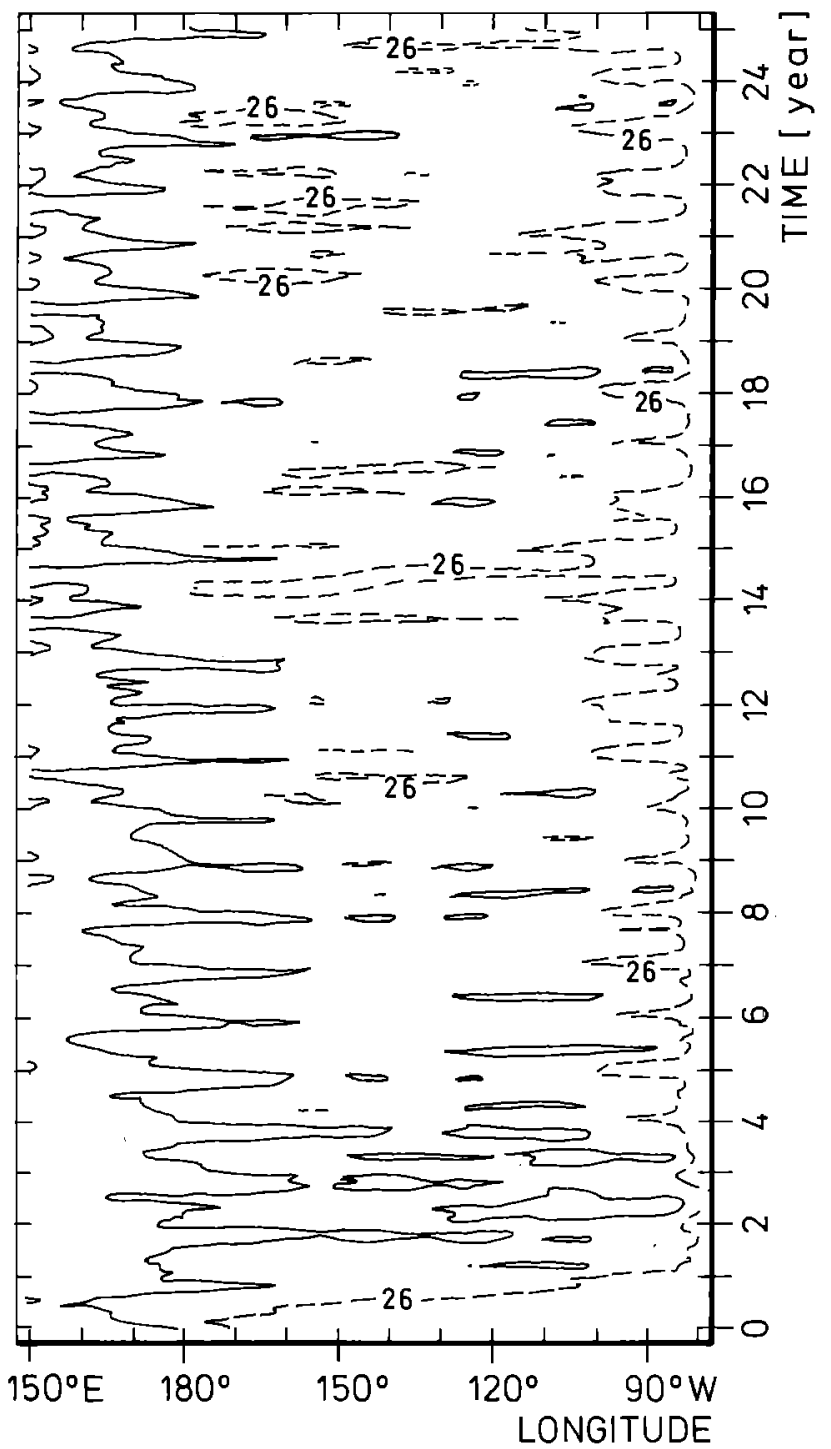

Fig. 11. Pacific SST averaged from $2^{\circ} \mathrm{S}$ to $2^{\circ} \mathrm{N}$ over 25 years of simulation by Cubasch and Böttinger (section 3.2c). Contour interval $1^{\circ} \mathrm{C}$, solid contour $27^{\circ} \mathrm{C}$

ble, might dampen feedback. On the other hand, the model climatological state itself resembles a permanent El Niño in that the cold tongue and Trade wind structure have collapsed to a large extent.

\subsection{Multi-level AGCMs with low-resolution OGCMs}

\section{a) Meehl and Washington}

Figure 12 shows SST-averaged from $10^{\circ} \mathrm{N}$ to $10^{\circ} \mathrm{S}$ over the last ten years of the coupled simulation, for longitudes from $50^{\circ} \mathrm{E}$ on the Indian Ocean to $80^{\circ} \mathrm{W}$ on the Pacific. Because the NCAR coupled model does not contain flux correction, simulated SST in the tropics are lower than observed. This cool water from the active upwelling in the model extends across the equatorial Pacific Ocean to the Indian Ocean with warmer water to the north and south in the tropical western Pa-

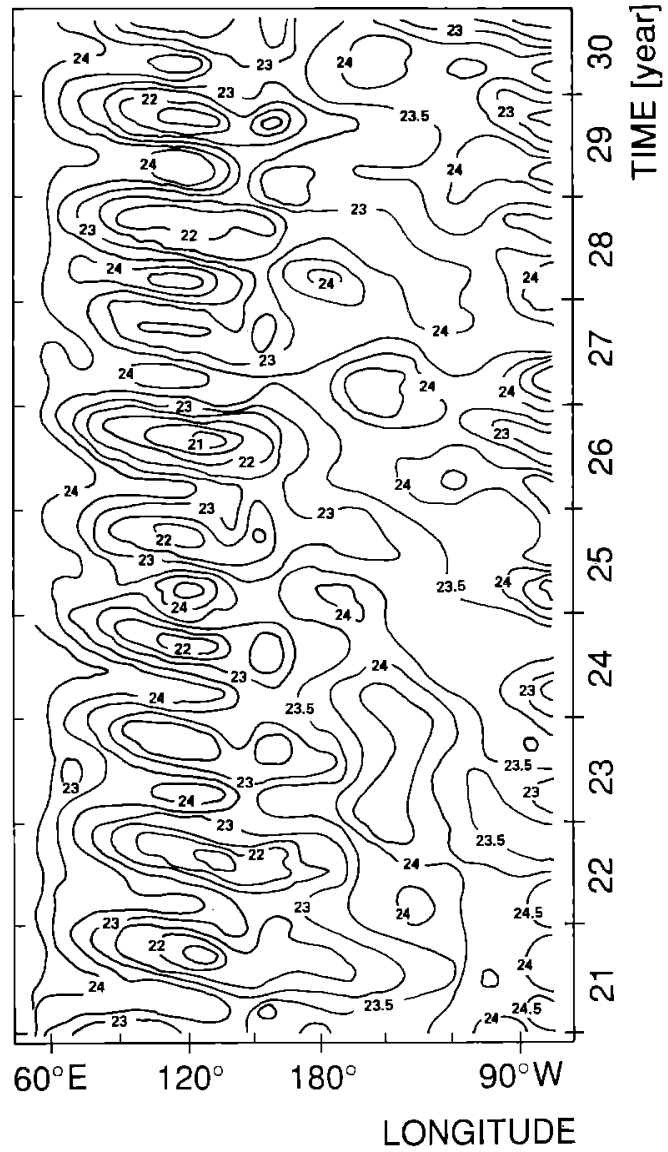

Fig. 12. Indian and Pacific SST averaged from $10^{\circ} \mathrm{S}$ to $10^{\circ} \mathrm{N}$ over 10 years of simulation by Meehl and Washington (section 3.3a). Contour interval $0.5^{\circ} \mathrm{C}$

cific. Meehl (1989) analyzed the source of this coupled model error for the tropical Indian and Pacific regions and concluded that the inherent limitations of the ocean model in resolution and geography contribute most to these errors. A slight drift of about $-0.02^{\circ} \mathrm{C} / \mathrm{y}$ is evident in the surface layer of the ocean over the 10 years shown.

In spite of the inherent limitations of the model and the errors in reproducing the climatology, the interannual variability in the tropical Pacific in the NCAR coupled model is pronounced. SST anomalies generally appear in the eastern Pacific and progress westward [figures of SST anomalies may be found in Meehl (1990a)]. Maximum amplitudes are roughly $\pm 1^{\circ} \mathrm{C}$. The establishment of SST anomalies greater than $\pm 0.5^{\circ} \mathrm{C}$ between about $110^{\circ} \mathrm{W}$ and the date line in the model occurs near the seasonal transition between MarchApril-May (MAM) and June-July-August (JJA). For example, northern spring seasonal transitions from warm to cold SST anomalies in this area occur in years 24 and 27 , while similar seasonal timing for transitions from cold to warm occurs in years 22 and 26. SST anomaly events with a duration of one year are present in the model near $110^{\circ} \mathrm{W}$ and the date line (e.g., the warm event starting in MAM of year 26 and ending after MAM of year 27). Two-year warm and cold events also 
occur (e.g., a warm event lasting from MAM year 22 to MAM year 24 and a cold event lasting from MAM year 24 to MAM year 26) and are analogous to single-year and multiyear events observed in the tropical Pacific (van Loon 1984).

Warm-water events in the model eastern Pacific are documented by Meehl (1990a) and correspond with low sea level pressure (SLP) in the eastern Pacific, high SLP over Indonesia and vice versa for cold events, similar to the association between Tahiti and Darwin SLP and observed warm and cold events. Analysis of composite warm events in the model shows strong Trades along the equator cause Ekman divergence in the upper layer of the ocean model, and the cooler water from the second layer is then brought to the surface. This upwelling process maintains low SSTs in the equatorial Pacific. When the easterly trade winds in the model slacken, the upwelling decreases. This means that less cool water from the second layer in the model reaches the surface and SSTs are higher. Simplistically, this can also occur in the observed ocean-atmosphere system in the tropical Pacific. However, the relationship between upwelling and SST in the real system depends critically on the depth of the thermocline. Since the thicknesses of the upper two layers of the ocean model are $50 \mathrm{~m}$ and $450 \mathrm{~m}$, the very close association between upwelling and SST in the model is not analogous in all respects to the real ocean.

When warmer water appears in the equatorial eastern Pacific as a result of the weakened easterlies and reduced upwelling in the model, lower pressure overlies this warm water, partly due to warming of the atmospheric boundary layer (Lindzen and Nigam 1987; Wallace et al. 1989). Associated increases in convection and precipitation also occur over the warmer water, as noted in the observations in the eastern Pacific (Gutzler and Wood 1990). The SLP gradient between the positive SLP anomalies in the central equatorial Pacific and the negative SLP anomalies in the eastern Pacific is established west of the positive SST anomalies, the westerly wind-stress anomalies set up by this surface pressure gradient extend farther west, upwelling is weakened, and SSTs become higher farther west during MAM. This set of coupled processes involving the atmosphere and the ocean continues to establish the positive SST anomalies farther west in the model until, by JJA, the positive SST anomalies almost reach the date line and positive SLP anomalies extend all the way to India. There, the positive SLP anomaly is associated with a suppression of the Indian Monsoon. This is analogous to the observed relationship between warm events in the Pacific and weak Indian Monsoons (Rasmusson and Carpenter 1983).

To investigate the sensitivity of coupled processes in the model to alterations of forcing, the coupled model was first run for five years with the wind-stress forcing from the atmospheric model reduced to 0.25 of the original values (Meehl 1990a). Virtually no interannual SST variability and no longitudinal movement of anomalies exist in the reduced wind-stress experiment. A second sensitivity experiment was run for six years with the solar insolation fixed at its mid-March value. Anomalies in the coupled model still occasionally form and tend to move from east to west but the regular formation and progression of anomalies seen in the seasonalcycle version is not reproduced.

\subsection{Low vertical resolution AGCMs with low-resolution OGCMs}

\section{a) Gates, Han and Schlesinger}

Figure 13 shows equatorial SST over a 16-year segment of the coupled run. The coupled model simulates a climate which is similar in most respects to that produced by the uncoupled atmospheric GCM (with climatological sea-surface temperatures); a major exception is the coupled model's failure to simulate a realistic seasonal distribution of surface wind, sea-surface temperature and precipitation over the tropical Pacific Ocean. In

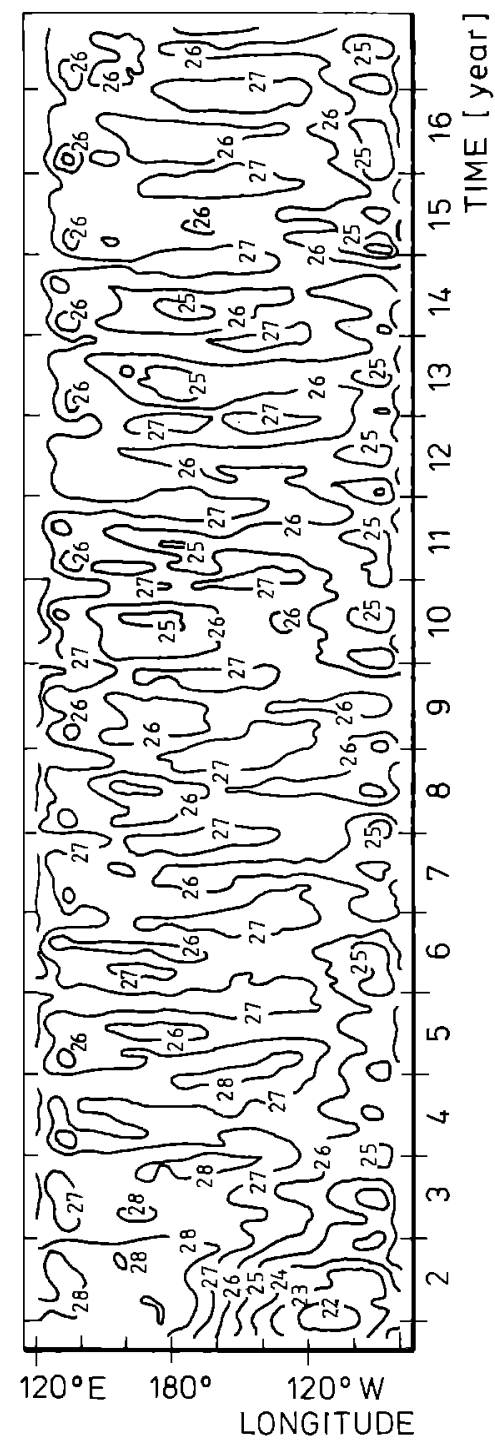

Fig. 13. Pacific SST along the equator over 16 years of simulation by Gates et al. (section 3.4a). Contour interval $1^{\circ} \mathrm{C}$ 
January the coupled GCM simulates an El Niño-like collapse of the Trades and the appearance of warm water across the equatorial Pacific; however, this occurs every year as part of the model's seasonal cycle, rather than as a sporadic interannual event. The major errors in the simulated sea-surface temperature itself are excessively cold water off the east coasts of Asia and North America, and excessively warm water off the western coasts of the tropical continents where the model fails to maintain the cold water induced by upwelling. These errors are due to errors in the simulated surface heat balance, and cause a progressive loss of sea ice in the southern ocean, while the Arctic sea ice is realistically simulated. The model's errors are partly due to the coarse resolution used (especially in the ocean) and partly to the systematic errors in the atmospheric model itself.

In an effort to isolate the cause of the model's errors, a heat budget analysis of the upper ocean has been made using the simulated data. The results indicate that the relatively rapid initial warming in the eastern tropical oceans is due to excessively large downward insolation during summer. The less-than-observed cloud amount simulated in these regions is the probable cause of this insolation error. The SST errors in the western oceans are mainly due to the excessively large latent and sensible heat fluxes simulated there during winter. The fact that the regional patterns of these particular SST errors coincide with those of the simulated Aleutian and Icelandic lows indicates a significant contribution to the error by the erroneous atmospheric surface wind. Further analysis of this run is described in Gates et al. (1985).

\section{b) Gates and Sperber}

Figure 14 shows the temporal evolution of the tropical Pacific SST ( $2^{\circ} \mathrm{N}-2^{\circ} \mathrm{S}$ average) for years 3-15 of the 25 -year simulation. As observed, the SST annual cycle in the eastern Pacific is prominent, with SST there reaching a seasonal maximum early in the calendar year. There is evidence of weak eastward propagation in the eastern Pacific, particularly from April through November, contrary to observations. Simulated eastward equatorial currents in the eastern Pacific, which suppress the upwelling of cold water near the coast of South America, an insufficient penetration of cold midlatitude water into the tropics by the Peru Current, contribute to the maintenance of SST in the region at values which are close to observed but which are warmer than simulated values through the central Pacific. The SST in the western Pacific is $\sim 4-8^{\circ} \mathrm{C}$ too cold, and the simulated east-west temperature gradient is much weaker then observed. The lowest simulated SST is in the central Pacific where the South Equatorial Current is established throughout the year. As observed, the simulated annual cycle in the western-central Pacific $\left(140^{\circ} \mathrm{E}-160^{\circ} \mathrm{W}\right)$ is weak, and this region shows the largest secular decrease in SST during the simulation. The behavior of the globally averaged surface air tem-

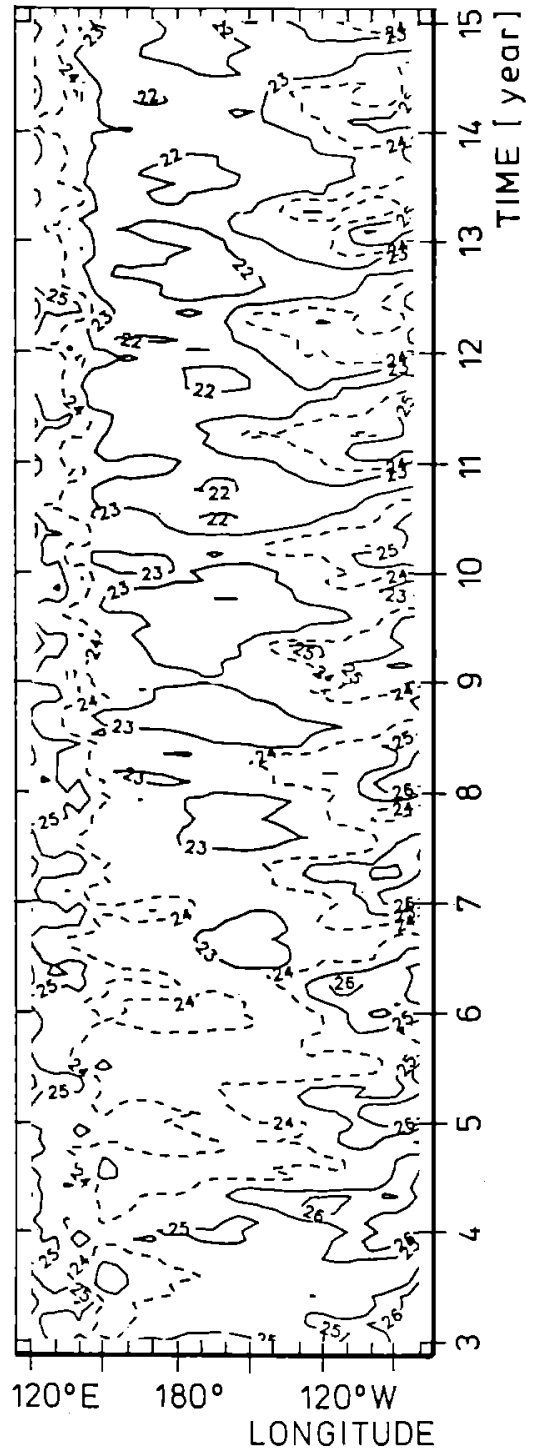

Fig. 14. Pacific SST averaged from $2^{\circ} \mathrm{S}$ to $2^{\circ} \mathrm{N}$ over 12 years of simulation by Gates and Sperber (section 3.4b). Contour interval $1^{\circ} \mathrm{C}$

perature and SST during the course of the simulation shows $\sim 2^{\circ} \mathrm{C}$ cooling, which has been ascribed to an overestimation of oceanic vertical mixing in the tropics (Gates and Potter 1991 submitted to Climate Dynamics).

While the simulated mean state departs from observed climatology, the model exhibits variability on the interannual time scale that is qualitatively characteristic of the Southern Oscillation. Sperber et al. (1987), Sperber (1989), Hameed et al. (1989), and Sperber and Hameed (1991) have found that the model simulates SLP, surface air temperature, precipitation, SST, thermocline temperature and slope, and surface current anomalies consistent with the opposing phases of the Southern Oscillation. This model simulates the observed anti-correlation of annually averaged sealevel pressure between the eastern Pacific and the Indonesian region, the primary atmospheric signal of the Southern Oscillation. 
In the composite of the simulated warm events positive SST anomalies expand eastward towards South America from the tropical western Pacific during the first half of the calendar year. The SST anomalies develop in conjunction with eastward mixed-layer current anomalies in the tropical Pacific. In the late summer and early fall, anomalously warm water near South America develops and moves westward to merge with the central Pacific anomalies. This lagged development in the eastern Pacific is analogous to the evolution of the 1982/83 and 1986/87 El Niños. The temperature of the thermocline layer also increases, with the slope of the equatorial Pacific thermocline decreasing in response to the relaxation of the surface forcing. Enhanced precipitation occurs in the mid-Pacific. The peak of the warm phase occurs in late northern fall/ early winter, somewhat earlier than during observed El Niños. The cold phase of the Southern Oscillation evolves in a fashion similar to the warm phase with the signs of the anomalies reversed, similar to observations. Additionally, Currie and Hameed (1988) have found evidence of the quasi-biennial oscillation in the simulation. The model's simulation of North Pacific Oscillation and North Atlantic Oscillation are described in Hameed and Pittalwala (1991) and Pittalwala and Hameed (1991) respectively.

\subsection{Simple atmospheric models with high-resolution OGCMs (hybrid coupled models)}

\section{a) Neelin}

The model has been run for a variety of different parameter values. Three runs are described here, of which one was among the runs presented in Neelin (1990). The runs differ in the value of the relative coupling coefficient and in initial conditions. The relative coupling coefficient measures the strength of wind stress anomalies produced by the atmospheric model relative to the strength with the standard parameter settings which are used in Run-1 (i.e., relative coupling coefficient 1.0). Run-1 begins with initial conditions from the model climatology which is in balance (by one-way flux correction) and would remain stationary except that it is unstable to perturbations. To this is added to a wind stress anomaly of $0.3 \mathrm{dyn} \mathrm{cm}^{-2}$ during the first month of the run.

The resulting SST evolution is complex, as seen in Fig. 15, which shows a 15 year segment at the start of the 18 year run. An interannual oscillation of just under four years may be seen, superimposed on which is a secondary oscillation due to coupled Kelvin waves with a period near six months. The behavior of this model for runs in which the coupling is reduced has been described in Neelin (1990). The shorter period oscillation becomes stable, leaving the interannual oscillation as a periodic limit cycle at lower coupling. Neelin (1991) has shown, by use of distorted physics techniques, that the time scale of this limit cycle at lower coupling is essentially independent of equatorial wave propagation time scales.

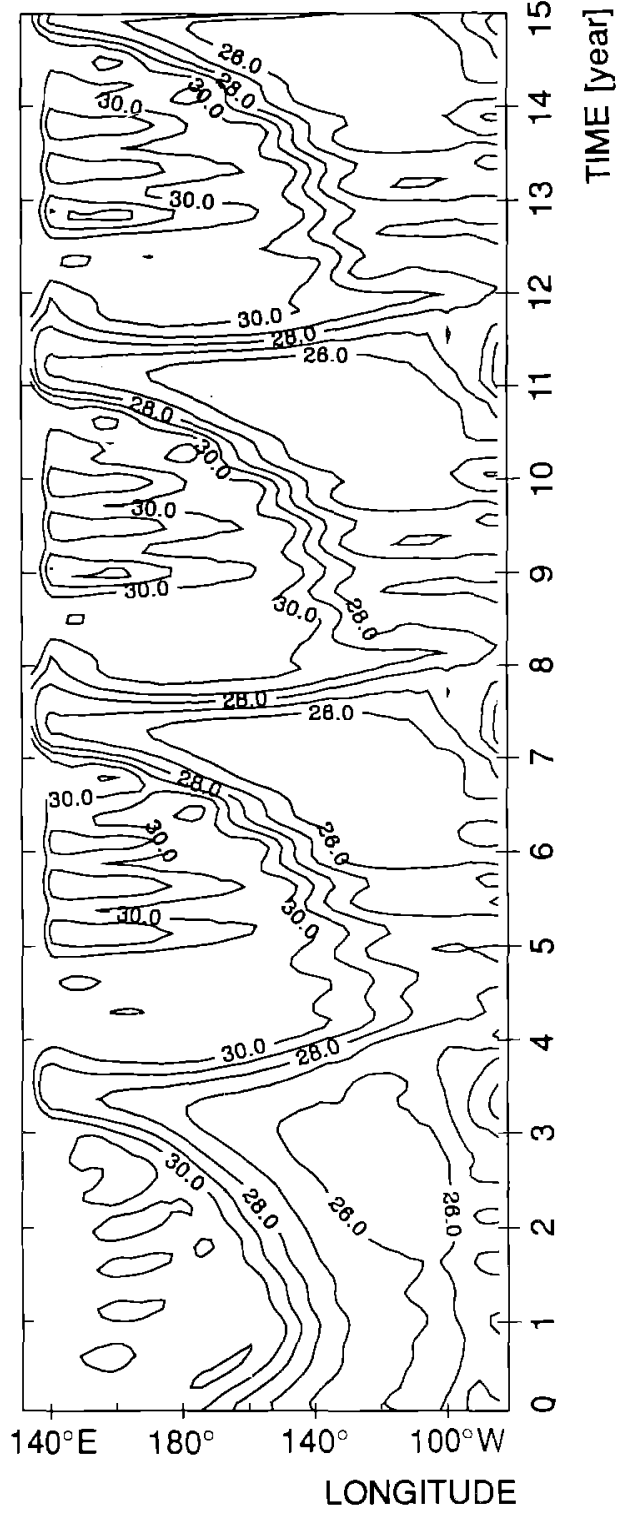

Fig. 15. Pacific SST along the equator over 15 years of simulation (without seasonal cycle) by Neelin (section 3.5a). A low-pass filter (half-power point at 6-months period) has been applied. Contour interval $1^{\circ} \mathrm{C}$

Runs 2 and 3 both use a relative coupling coefficient of 1.1, i.e., wind stress anomalies ten percent stronger than in Run-1 for a given oceanic state. Run-2 begins from the same initial conditions as Run-1, while Run-3 begins from conditions which are warm across the basin. In Run-2, the SST evolution (Fig. not shown) resembles that of Run-1 in having both interannual and shorter period oscillations. It differs in that the period of the interannual oscillation has increased to approximately five years due to an increase in the length of the warm phase, during which SST anomalies appear close to stationary. Propagation of SST anomalies is seen only during the transition between phases-slowly westward on entering the cold phase and rapidly eastward on entering the warm phase. Run-3, on the other hand remains permanently (over the eighteen years of the run; Fig. not shown) in a warm state, which is 
slightly warmer than the warm phase of Run-2. Six month coupled Kelvin wave oscillations still occur about this warm state.

Since the (unstable) climatology is a known stationary point of the model, this warm stationary point represents an additional steady state of the system (stable aside from the Kelvin wave cycle). In this case, it also coexists with the attractor found in Run-2 which contains the interannual oscillation. If the coupling is increased by an additional $10 \%$, then the interannual oscillation disappears, leaving the perpetual warm state as the only attractor. In the presence of stochastic forcing by atmospheric internal variability, the system in Runs 2 and 3 would alternate between periods spent in the different basins of attraction. These runs also serve as a strong indicator of the sensitivity of the coupled system, since parameter changes of only ten percent introduce qualitative changes in the coupled behavior.

\section{b) Allaart, Jansen, Kattenberg and Verhaar}

A twenty year coupled run was started from the nearly cyclo-stationary climatological state with no initial perturbation. Figure 16 shows the evolution of SST averaged over a band $8^{\circ}$ wide, centered on the equator. The anomalous activity that shows up in the coupled run occurs mainly in the western half of the basin. Except

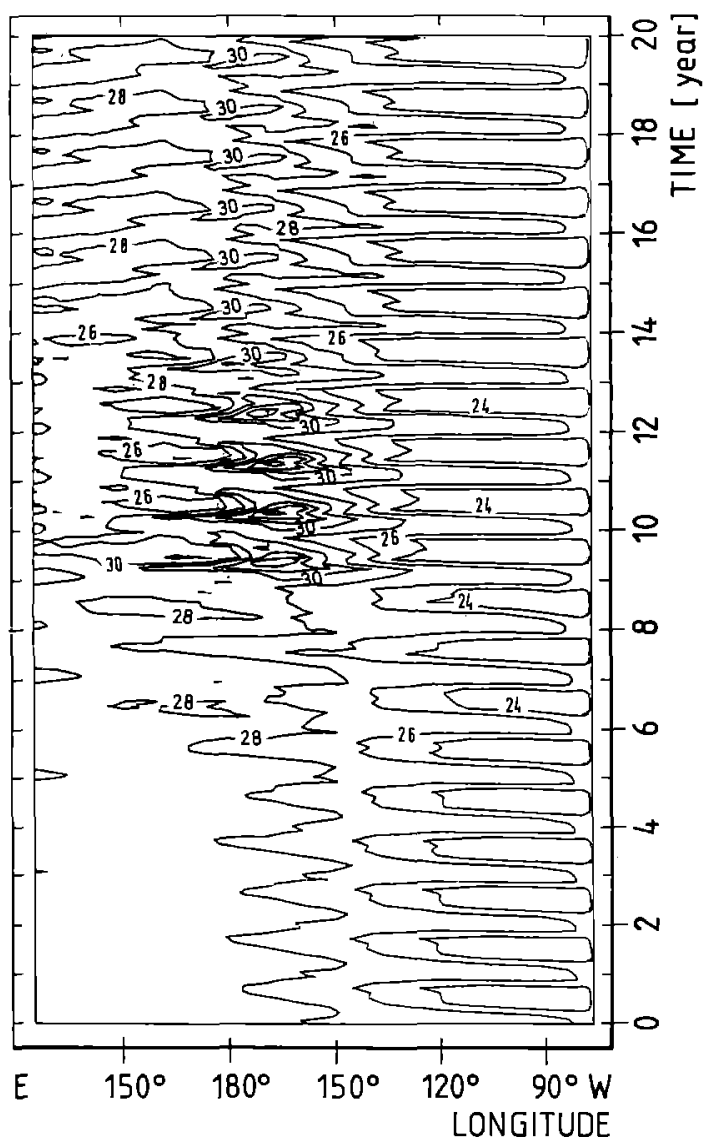

Fig. 16. Pacific SST averaged from $4^{\circ} \mathrm{S}$ to $4^{\circ} \mathrm{N}$ over 20 years of simulation by Allaart et al. (section 3.5b). Contour interval $2^{\circ} \mathrm{C}$ for marked surface salinity changes, anomalies in the eastern quarter of the basin along the equator remain relatively small at all times. The anomalous activity is also modulated in time, with the strongest anomalies occurring in the northern-summer months and the weakest ones in December and January.

The 20-year run shows three periods of qualitatively different behavior. At first, during year 1 to 9 the coupled system maintains the initial climatology. SST anomalies along the equator remain less than $1^{\circ} \mathrm{C}$ with wind anomalies less than $1 \mathrm{~m} \mathrm{~s}^{-1}$, and variability of the undercurrent looks like the climatology (between 60 and $100 \mathrm{~Sv}$ ).

During year 10 to 14 strong variability arises: SST anomalies are of the order of $5^{\circ} \mathrm{C}$ with zonal wind anomalies of the order of $5 \mathrm{~m} \mathrm{~s}^{-1}$, while the strength of the undercurrent shows large, one-sided excursions. Strong negative anomalies in the transport of the current occur at a point that coincides with the position and time of strongest zonal wind anomaly and are seen to propagate with Kelvin and Rossby wave speed towards the east and west, effectively shutting down all transport in the undercurrent during the northern-summer months.

Finally, during year 15 to 20 the coupled system seems to have found a new cyclo-stationary climatic state with SST anomalies of the order of $2^{\circ} \mathrm{C}$, wind anomalies of the order of $2 \mathrm{~m} \mathrm{~s}^{-1}$ and slightly enhanced undercurrent variability (between 60 and 110 $\mathrm{Sv})$.

The surface salinity shows a development that is worth noting: The first seven years are nearly climatological. Then, in year 8 , a strong positive anomaly ( 1 part per thousand) suddenly develops in the westernmost $20 \%$ of the equatorial strip and persists without much modulation or development during years 9 to 20 . From year 8 to 14 a similar positive anomaly develops (more slowly) in the easternmost $20 \%$ of the equatorial strip. After year 14 it does not develop any further. This eastern salinity anomaly is modulated by the seasonal cycle. The central-western basin SST anomaly activity in year 10 to 14 is accompanied by strong ( 1 part per thousand) negative salinity anomalies coinciding with the warmest regions and episodes. These anomalies disappear after year 14 .

A different version of the atmospheric model heating scheme in which the shape of the vertical heating profile changes as a function of SST has also been used. A coupled integration with this version produced stronger wind anomalies, which led to an unacceptably strong cooling in the western Pacific (several degrees per year).

\subsection{Simple atmospheric models with low-vertical high-horizontal resolution OGCMs}

\section{a) Schopf and Suarez}

The coupled integration has a duration of 35 years beginning from rest. Five years were allowed for the system to equilibrate and the last 30 years were analyzed. SST evolution over a representative 15 -year period is 
shown in Fig. 17, which is reconstructed from the corresponding mean and anomaly figures of Schopf and Suarez (1988). The climatology of SST shows a pronounced cold tongue along the equator in the eastern and central Pacific with a minimum temperature of $22^{\circ} \mathrm{C}$. The warm pool temperatures in the west are too cold, attaining a maximum of $26^{\circ} \mathrm{C}$, and the meridional temperature gradient is generally weaker than observed. A small patch of equatorial westerlies in the fareastern part of the basin produces warm temperatures at the eastern coast.

Interannual variability in SST is dominated by time scales of 3 to 5 years, with a succession of standing warm and cold anomalies in the cold tongue region, centered near $130^{\circ} \mathrm{W}$. Equatorial wind stress anomalies are strongly linked to SST anomalies, with maximum westerlies/easterlies occurring to the west of the warm/ cold anomalies, centered near $160^{\circ} \mathrm{W}$. The oscillatory behavior of this system has been analyzed in Schopf and Suarez (1988), Schopf and Suarez (1990), and was the basis for the delayed-action oscillator proposed in Suarez and Schopf (1988). In this model, the growth of SST anomalies in the eastern Pacific by positive feedback between wind stress and SST produces off-equatorial heat content anomalies of opposite sign which propagate westward as an oceanic Rossby wave packet and are reflected from the western boundary as a Kelvin wave packet. Upon arrival in the region of strong

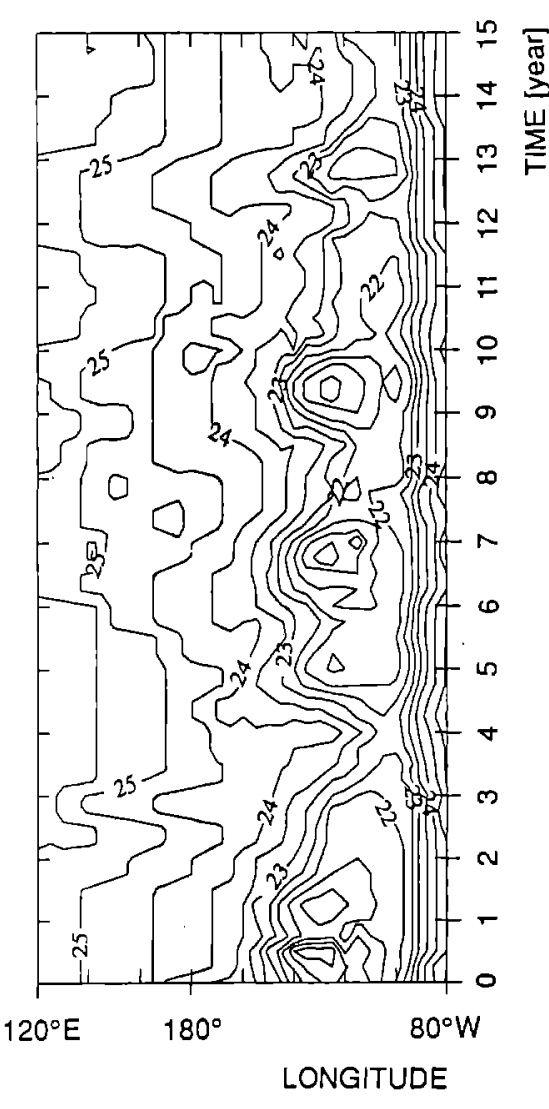

Fig. 17. Pacific SST along the equator over 15 years of simulation by Schopf and Suarez (section 3.6a). Contour interval $0.5^{\circ} \mathrm{C}$ coupling in the east, these heat content anomalies reverse the SST tendency and local feedback processes produce a growing SST anomaly of opposite sign to the original. The second half of the cycle then occurs as above, but with the signs reversed. Roughly speaking, the time scale of the coupled oscillation is set by twice the time scale typical of propagation from the coupling region to the western boundary and back, plus an additional time typical of the growth phase.

In an additional experiment, the atmospheric model was replaced by a linear version. The interannual oscillation became periodic, while the time scale decreased to a period of 30 months. In this case, slow eastward propagation of SST anomalies may be noted in the eastern part of the basin, while subsurface evolution in the west occurs much as in the previous case.

The results were found to be sensitive to the thickness of the second ocean layer. Furthermore, the temperature of the abyssal water and its entrainment into the modeled part of the system were crucial in determining whether the system oscillated, or became permanently warm or permanently cold.

The dependence of the behavior on an unmodeled part of the solution (the abyss) was felt to be a deficiency of the Schopf and Suarez (1988) ocean model. To overcome these defects and to generally improve the overall fidelity of the oceanic solution, a new model was built, as described at the end of section 2.6a. Only

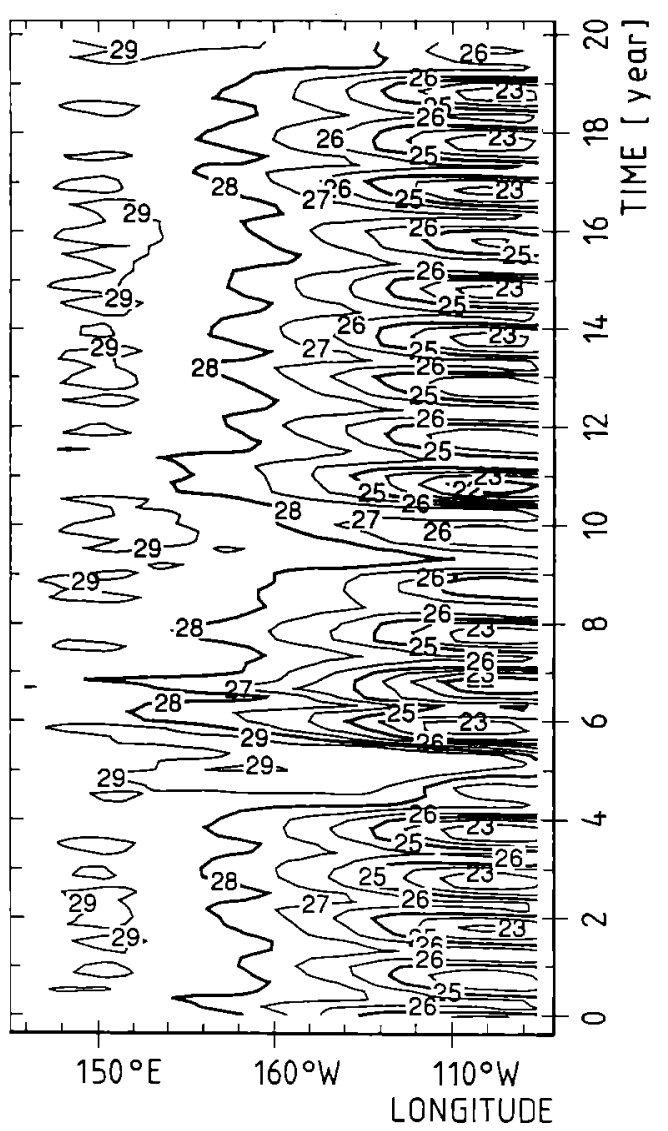

Fig. 18. Pacific SST along the equator over 20 years of simulation by Zebiak and Cane (section 3.6b). Contour interval $1^{\circ} \mathrm{C}$ 
preliminary analysis of a 1.5 year integration with this coupled model is available (no Fig. shown). The system immediately enters an El Niño-like state with the warmest water in the eastern Pacific and general cooling through the rest of the basins. These deficiencies may be attributed to the atmospheric model which produces only half the observed zonal wind stress near the equator and a surface heat flux which tends to cool the warmest water when run with climatological conditions.

\section{b) Zebiak and Cane}

The SSTs over a 20-year simulation period (Fig. 18) show typical model behavior: warm events of varying intensity are aperiodic, but with a definite preference for 3-4 year cycles. The very weak anomalies between years 0 and 3, and between years 12 and 18, are contrasted with an energetic cycle between years 4 and 11 , and again following year 18. As is typical of this model, the evolution of equatorial anomalies is characterized by a nearly stationary pattern, with maximum amplitude in the east Pacific, and minimum amplitude west of the dateline. The total SST field is of course dominated by the annual cycle, but shows large eastward excursions of the 28 and 29 degree isotherms during the three model warm events of the period.

Table 2. Summary of models grouped according to common behavior for both tropical climatology and interannual variability as reflected in the sea surface temperature field.

For the climatology, the category 'no obvious drift' refers to models for which SST has equilibrated to a state comparable to uncoupled control runs. 'Prescribed or flux-corrected' refers to models which introduce a correction to keep the model near climatology or create a climatological stationary point or annual cycle.
The mechanisms, predictability and predictive skill of this model and closely related versions have been examined by Zebiak and Cane (1987), Cane et al. (1986), Battisti (1988), Battisti and Hirst (1988) and Goswami and Shukla (1991).

\section{Discussion}

Table 2 summarizes the results of the above section according to common behavior for both tropical climatology and interannual variability as reflected in the sea surface temperature field. Many of the coupled models exhibit what is commonly referred to as 'climate drift'. Here, we use this term to refer both to a slow drift away from climatology over the course of decadal runs and to relatively fast adjustments leading to a state which is significantly different from normal climatology. The latter is characteristically a coupled dynamical effect, leading to an overly weak or overly strong equatorial cold tongue.

For the climatology, the category 'no obvious drift' in Table 2 refers to models for which the SST has approximately equilibrated to a statistically steady state comparable to uncoupled control runs with climatological forcing and qualitatively comparable to observa-
The category 'other' combines results for climatologies differing significantly from that observed; the main features are indicated in brackets. For the interannual variability, the categories 'zonal propagation of SST anomalies' and 'standing SST anomalies' are subjective measures-comments are indicated in brackets. Models for which integrations are too short to permit classification of interannual variability are not included in the table but are discussed in the text

\begin{tabular}{|c|c|c|c|}
\hline \multirow[t]{2}{*}{ Variability } & \multicolumn{3}{|l|}{ Climate } \\
\hline & $\begin{array}{l}\text { No obvious } \\
\text { drift }\end{array}$ & $\begin{array}{l}\text { Prescribed or } \\
\text { flux-corrected }\end{array}$ & Other \\
\hline $\begin{array}{l}\text { Weak } \\
\text { interannual } \\
\text { variability }\end{array}$ & & $\begin{array}{l}\text { Latif et al. } \\
\text { (cool equatorial SST) } \\
\text { Neelin Run-3 } \\
\text { (warm stationary state co-exists) } \\
\text { Oberhuber et al. Run } 1 \\
\text { (weak events in West Pacific) }\end{array}$ & $\begin{array}{l}\text { Gordon and Ineson Run-2 } \\
\text { (initial warming, then slow cooling) } \\
\text { Gates et al. } \\
\text { (weak zonal gradient) } \\
\text { Cubasch et al. } \\
\text { (weak zonal gradient) } \\
\text { Oberhuber et al. Run-2 } \\
\text { (weak equatorial cold tongue) }\end{array}$ \\
\hline $\begin{array}{l}\text { Interannual } \\
\text { variability } \\
\text { with zonal } \\
\text { propagation } \\
\text { of SST } \\
\text { anomalies }\end{array}$ & Lau et al. & Neelin Run-1 & $\begin{array}{l}\text { Meehl and Washington } \\
\text { (upwelling extends along equator) } \\
\text { Gates and Sperber } \\
\text { (upwelling in mid-Pacific) } \\
\text { Tokioka et al. } \\
\text { (cool equatorial SST) } \\
\text { Mechoso et al. Run-2 } \\
\text { (perpetual January) }\end{array}$ \\
\hline $\begin{array}{l}\text { Interannual } \\
\text { variability } \\
\text { with } \\
\text { standing SST } \\
\text { anomalies }\end{array}$ & $\begin{array}{l}\text { Philander et al. } \\
\text { Gent and Tribbia }\end{array}$ & $\begin{array}{l}\text { Zebiak and Cane } \\
\text { Allaart et al. } \\
\quad \text { (alternate climate states?) }\end{array}$ & $\begin{array}{l}\text { Schopf and Suarez } \\
\text { (cool tropical SST) } \\
\text { Latif and Sterl } \\
\text { (cooling in West Pacific) }\end{array}$ \\
\hline
\end{tabular}


tions. 'Prescribed or flux-corrected' refers to models which introduce a correction to keep the model near climatology or create a climatological solution. Although zero anomaly is defined to be a solution in these models, interesting behavior arises through instability of this solution in the coupled system. It may also be noted that, while, in principle, a stationary solution constructed by flux correction has zero anomalies, in practice small anomalies may be found due to imperfections in the formulation. The category 'other' combines results for climatologies differing significantly from that observed or simulated in the uncoupled components. The main features of these differences are indicated in brackets in each case.

For the classification of interannual variability in Table 2, the categories 'weak interannual variability', 'interannual variability with zonal propagation of SST anomalies' and 'interannual variability with standing SST anomalies' are certainly subjective measures. The distinction between propagating and standing SST anomalies appears to be the simplest available way of dividing the oscillating cases, and this criterion bears some relation to simple model results. Comments are included in brackets where further explanation seemed necessary, especially where the behavior did not fit neatly into the assigned category. Interannual variability is weaker than observed in several models; the category 'weak interannual variability' refers to cases where it is too weak to be readily classified.

\section{Climate drift}

We summarize these tendencies briefly as follows. In Latif et al. the SST along the equator cools by about $1^{\circ} \mathrm{C}$ in the west and $2^{\circ} \mathrm{C}$ in the east due to the combined effects of mixing and equatorial upwelling. This occurs despite the application of flux correction. SST outside the equatorial upwelling region is relatively constant. Equatorial cooling due to the effects of upwelling is even more significant in Meehl and Washington where upwelling extends across much of the equatorial band, cutting through the region where the Indonesian warm pool would normally be. The warmest SST in the Pacific averaged from $10^{\circ} \mathrm{N}$ to $10^{\circ} \mathrm{S}$ (about $24^{\circ} \mathrm{C}$ ) occurs in the far eastern Pacific and in the far western Pacific only during northern spring. Stresses tend to be strong in this atmospheric model, so this case may be regarded as one with strong coupling. The Gates and Sperber run has many parallels to this result, with generally cold equatorial SSTs and the cold tongue occurring in mid-Pacific. Again, the east Pacific SSTs are slightly warmer than in the west. It is worth noting that the climate drift does not prevent either of these two models from having significant and in many ways realistic interannual variability. In Tokioka et al., the zonal extent of the warm pool along the equator decreases slowly over 8 years. Again the water in midbasin tends to be cool and warm water appears in the east during part of the year.

In contrast to the above, several of the models exhibit a weakened cold tongue, with weak zonal gradients across the equator. The Cubasch et al. run drifts within the first year to a state with weak zonal gradients. The cold tongue is weak with water cooler than $26^{\circ} \mathrm{C}$ occurring only very near the eastern coast. The ocean model forced by observed winds does produce a reasonable cold tongue, so this behavior is a feature of the coupling. Oberhuber et al. Run-1 exhibits a similar rapid drift into a permanent warm state with no equatorial cold tongue. Preliminary results from the new Schopf and Suarez model suggest similar behavior. In Oberhuber et al. Run-2, the warm pool exhibits a tendency to extend slowly eastward over a decade, despite the fluxcorrection, with the $28^{\circ} \mathrm{C}$ isotherm moving from the date line to $150^{\circ} \mathrm{W}$. In the integration presented by Gates et al., the model drifts within less than 2 years to a weak cold tongue condition, while the warm pool region cools more slowly. The zonal gradient is weak overall, but exhibits seasonal variation, with warm water tending to appear annually in the center of the basin. In Gordon and Ineson Run-1, the warm pool tends to occur more in the central part of the basin than observed, depending on the season. This tendency manifests itself immediately in the model integration. Western temperatures tend to be a degree too cold and eastern temperatures a few degrees too warm. In Mechoso et al. Run-1, the cold tongue is weak and warm water is displaced across the basin in all seasons, modulated by the migration of the ITCZ between hemispheres. A similar migration of the ITCZ between hemispheres, even in the eastern and central Pacific where the observed ITCZ remains north of the equator, is noted in Latif and Sterl.

The Richardson-number-dependent vertical-mixing schemes used in Gordon and Ineson Run-1, Mechoso et al. Run-1 and Latif and Sterl tend to yield small vertical mixing when large incoming surface heat flux stabilizes the upper layers. Under such conditions, the small heat capacity of the shallow mixed layer allows the SST south of the equator to warm during the Southern Hemisphere summer. The ITCZ tends to follow the warm water into the summer hemisphere and the wind pattern that would maintain the cold water south of the equator in the observed climatology is disrupted, thus allowing further warming. The interaction of the surface fluxes with the vertical-mixing parameterization thus apparently sets off a whole chain of coupled processes which result in a climatic state departing significantly from the observed. Uncoupled tests with the AGCMs and OGCMs often do not immediately reveal anything obviously wrong with these parameterization schemes, which may function very well in other situations. For instance, these three models use oceanic vertical-mixing schemes and OGCMs very similar to Philander et al. (although with seasonal cycle included and with different AGCMs) and the latter experiences little drift.

In Gordon and Ineson Run-2 (the new version), the climatological features and seasonal cycle are reproduced in qualitative terms, although the integration exhibits both slow and fast adjustments of the climate during the course of the run. Initially, the ocean falls 
quickly into a warm state with a weak zonal SST gradient along the equator which persists for about 5 years. Thereafter, the ocean slowly drifts toward colder conditions in which the equatorial cold tongue extends considerably further to the west than normal. Weak indications of a similar return toward a stronger cold tongue after an initial warming may be found in the Cubasch et al. integration. Latif and Sterl also report gradual cooling in the western Pacific and warming in the far eastern Pacific after an initial warm period.

In Philander et al., the SST drifts relatively little over the course of the run presented here. The main deviation from observed climatology occurs at the eastern edge of the basin, where a small area of warm water appears due to westerly winds off the coast of South America. The same feature occurs in the Lau et al. model and in several other models (namely, Latif and Sterl; Tokioka et al.; Gates and Sperber and Schopf and Suarez). In Lau et al., the SST climatology is also reasonable although the cold tongue is not as strong, reaching a minimum slightly less than $26^{\circ} \mathrm{C}$. In both of these runs, the reasonable climatology of SST is obtained despite having atmospheric wind stresses weaker than observed. It is worth noting that the GFDL Climate group AGCM used in these runs has prescribed, zonally symmetric clouds, and also has a long history as a climate model, having previously been run with a variety of lower boundary conditions, including zero heat capacity moist continent (swamp) conditions and ocean mixed layer conditions. Two preliminary runs of the Philander et al. model with interactive clouds indicated a greater tendency to climate drift when this additional degree of freedom is included.

\section{Interannual variability}

Surprisingly, climate drift appears not to be the major determining factor in the nature of coupled variability found in these coupled models. Models with near-observed or far-from-observed mean SSTs and upwelling can still exhibit interannual variability with qualitatively similar characteristics, while models whose mean SST fields are similar can exhibit very different interannual behavior. Furthermore, a good simulation of the seasonal cycle does not guarantee that interannual oscillations will occur, as seen in Gordon and Ineson Run-2.

A number of the models exhibit little interannual variability or interannual variations of very small amplitude. Even this absence of oscillation apparently arises for different reasons in different models. One reason which is fairly well understood is insufficient coupling strength in the part of the flow which deviates from climatology, as found in Schopf and Suarez (1988), Neelin (1990), and Meehl (1990a). If the coupled feedbacks which lead to instability of the climate state to interannual oscillations are not sufficiently strong compared to the processes which tend to damp these instabilities, then perturbations tend to decay back to the climatology. What constitutes "sufficient coupling strength" depends on a variety of model parameters. In Latif et al., possible reasons include an overly strong cold tongue, weak wind stress response to SST and possibly the effects of the flux correction method. The latter two reasons may apply also to Oberhuber et al. Run-2, although the effects of coarse meridional resolution on wave dynamics may also play a role. It appears that the model must fulfill certain conditions for flux correction to be successful. For instance, if the anomalies of wind stress are weaker than realistic magnitude, then correcting weak mean easterlies using observed stress is likely to disfavor oscillations.

Models in which the cold tongue is permanently or seasonally weak tend not to have strong interannual variability. In Gordon and Ineson Run-1, Mechoso et al. Run-1 and Gates et al., there is an annual collapse of the Trade winds and El Niño-like warm conditions across the Pacific basin but the interannual variation of this is weak. In Cubasch et al. and Oberhuber et al. Run-1, where there is a permanent collapse of the trade winds and the cold tongue does not develop strongly during any season, weak warm or cold events of short duration occur only sporadically in various parts of the basin. Permanent warm conditions also occur in Neelin Run-3 where a warm stationary state is found for coupling only $10 \%$ higher than the best-estimate parameter values. The climatological stationary state still exists in this case, although it is unstable. Similar behavior has been noted in the hybrid model of Latif and Villwock (personal communication). These results bear out the suggestion, noted by several modeling groups, that the permanent warm conditions appear to be maintained by coupled feedbacks similar to those responsible for El Niño. They also suggest that some of the other model runs which find permanent warm conditions might give much more realistic behavior with relatively small changes in parameters. The striking improvement between Gordon and Ineson Run-1 and Run-2 may provide further indication of this.

Among the models that do oscillate on interannual time scales, similarity may be found between Lau et al., Meehl and Washington, and Neelin Run-1. All show westward phase propagation of SST, with coherent wind stress patterns and oceanic circulation anomalies. The interannual variability in Tokioka et al. and Mechoso et al. Run-2 appears to follow a similar pattern. The role of phase propagation in Gates and Sperber is less clear, although movement of the SST anomaly within the basin is a significant feature of the development; SST anomalies which develop in the western Pacific merge with those developing in the eastern Pacific in northern fall. Oscillations in the zonally propagating class are controlled by advective processes and the relative zonal phase of temperature anomalies, wind stress and the resulting current and thermocline anomalies. Meehl (1990a) suggests that anomalous upwelling is the important factor in producing the SST anomalies. Lau et al. (1992) find that zonal, meridional and vertical advection can all be significant in producing the SST anomalies. Neelin (1991) suggests that these mechanisms 
plus an additional feedback involving thermocline displacements contribute to the oscillation in Neelin Run1. Equatorial wave dynamics does not appear to be crucial to this class of oscillations. Coarse horizontal resolution in the ocean model (as in Meehl and Washington and Lau et al.) clearly does not preclude interannual oscillations of this type.

The models of Zebiak and Cane and Schopf and Suarez exhibit interannual oscillations with standing SST anomalies. The oscillation mechanisms in these two models have been the subject of considerable investigation (Battisti and Hirst 1988; Suarez and Schopf 1988; Schopf and Suarez 1990; Cane et al. 1990) and oceanic wave propagation is believed to play an important role. Latif and Sterl also found equatorial wave dynamics to be important and the mechanism responsible for the long-period oscillation in Philander et al. appears to share a similar dependence on the oceanic subsurface memory and the adjustment time scale of wave dynamics in the basin. The Gent and Tribbia model oscillation has not been thoroughly analyzed at this time, but appears a candidate for this type of mechanism.

\section{Concluding remarks}

The rich variety of coupled phenomena found in these models serves as an indication of the sensitivity of the coupled system. Not only does there appear to be more than one mechanism of producing interannual variability in these models, but coupled feedbacks can also strongly affect the climate of the coupled system. Even the most important features of the observed tropical climatology, such as the extent and position of the equatorial cold tongue and western Pacific warm pool are not guaranteed to be reproduced in coupled GCMs. The lack of robustness in these features does not necessarily imply major faults in the models since coupled feedbacks can turn a small deficiency in one of the components into a significant departure in the coupled climatology. For example, a tendency of the atmospheric model to give slightly weak easterlies can result in a weaker cold tongue which in turn further weakens the Trades. In some models this can lead to a permanent warm state, although in others weak AGCM stresses do not adversely affect either climatology or interannual oscillations. Work with the hybrid class of models suggests that in some cases a small change in parameters can lead from a regime with interannual oscillations to one with a permanent warm state. If we extend the use of the term "parameter space" to include the gross effects of changes in model formulation, we may consider the diverse results of the CGCM experiments as being simply an indication of a high degree of sensitivity and of a complicated dependence upon the region in parameter space in which the different models reside.

The intercomparison of results presented here has mapped out a part of this parameter space. It is hoped that the framework which this provides will be of use in the further development of coupled models. Because the behavior of the coupled system can be qualitatively different (and difficult to anticipate) from that of the individual components, coupling should be regarded as a crucial part of the testing and development procedure for AGCMs and OGCMs being used for climate studies. While the sensitivity of the tropical coupled system represents a challenge for modelers, it also provides a test-bed for model parameterizations. Results presented here suggest that the simulation of the warm-pool/ cold-tongue configuration in the equatorial Pacific can represent a stringent test, especially of the combined effects of vertical-mixing parameterizations, interactive cloud-radiative schemes and surface flux parameterizations.

Implications for the problem of climate forecasting on seasonal to interannual time scales with coupled models also arise. Currently, only one coupled model is being used to carry out regular ENSO forecasts-that of Zebiak and Cane, in which climatology is specified. Among the CGCMs, a common mode of climate drift involves coupled interactions similar to those active in El Niño and occurs on time scales similar to the target phenomenon. Strategies for correcting the climatology in these models have met with mixed results but are often not conducive to simulation of interannual variability. Unlike numerical weather prediction models, in which correction of climate drift was only addressed as the models matured, this suggests that for ENSO forecasting, CGCMs must address the accurate simulation of the climatology at a relatively early stage.

The apparent presence of more than one possible source of interannual oscillation in the coupled models has further implications for observational requirements. The major classes of tropical interannual variability present in the models are consistent with a distinction between modes of oscillation which depend on slow zonal propagation of SST anomalies and those to which subsurface memory associated with equatorial wave dynamics is crucial. This suggests that traditional ENSO morphologies, such as that of Rasmusson and Carpenter (1982), may not be fully adequate for distinguishing between sources of variability in the models and that large-scale, long-term observations of subsurface thermal fields over the tropical Pacific basin are needed for model validation.

Acknowledgements. The compilation of this intercomparison was supported in part by NSF grant ATM-8905164 and by the MaxPlanck-Institut für Meteorologie. Initial redrafting of figures was carried out at MPI and drafting of revisions at UCLA was assisted by W. Weibel and L. Lee, supported under NOAA-TOGA grant NA16RC0178-01. C. Wong provided invaluable assistance in typesetting tables and successive revisions of the manuscript. We thank Dr. Y. Chao for providing figures of observed SST and Dr. T. Barnett for helpful comments in reviewing the manuscript. Appreciation is expressed to a number of co-workers in the various coupled modeling groups. While only those group members directly responsible for writing or editing the contributions to this intercomparison have been listed as coauthors, the following colleagues are acknowledged: J. Biercamp, M. Böttinger, M. Endoh, M. Fisher, Y. J. Han, D. Halpern, S. Ineson, D. Jansen, A. Kattenberg, F. Lunkeit, S. Manabe, T. Nagai, M. J. Nath, R. C. Pacanowski, R. Sausen, M. E. Schlesinger, J. Spahr, R. Stouffer, M. 
Suarez, J. Verhaar, H. von Storch, W. M. Washington, and F. W. Zwiers. Finally, the two lead authors thank the contributing authors for their patience, support and helpful comments throughout the process of assembling and editing the contributions and seeking relations among the models.

\section{References}

Allaart MAF, Kattenberg A (1990) A primitive equation model for the Equatorial Pacific. KNMI Technical Report TR-124

Arakawa A, Schubert WH (1974) Interaction of a cumulus cloud ensemble with the large scale environment, Part I. J Atmos Sci 31:674-701

Arakawa A, Lamb VR (1981) A potential enstrophy and energy conserving scheme for the shallow water equations. Mon Wea Rev 109:18-36

Arakawa A, Suarez MJ (1983) Vertical differencing of the primitive equations in sigma coordinates. Mon Wea Rev 111:3435

Barnston AG, Livezey RE (1987) Classification, seasonality and persistence of low-frequency atmospheric circulation patterns. Mon Wea Rev 115:1083-1126

Battisti DS (1988) The dynamics and thermodynamics of a warming event in a coupled tropical atmosphere/ocean model. J Atmos Sci 45:2889-2919

Battisti DS, Hirst AC (1988) Interannual variability in the tropical atmosphere/ocean system: influence of the basic state and ocean geometry. J Atmos Sci 45:1687-1712

Bjerknes J (1969) Atmospheric teleconnections from the equatorial Pacific. Mon Wea Rev 97:163-172

Bryan K, Lewis LJ (1979) A water mass model of the world ocean. J Geophys Res 84(C):2503-2517

Busalacchi AJ, O'Brien JJ (1981) Interannual variability of the equatorial Pacific in the 1960s. J Geophys Res 86:1090110907

Cane MA (1979a) The response of an equatorial ocean to simple wind stress patterns: I. Model formulation and analytic results. J Marine Res A 37:233-252

Cane MA (1979b) The response of an equatorial ocean to simple wind stress patterns: II. Numerical results. J Marine Res 37:253-299

Cane MA (1986) El Niño. Annu Rev Earth Planet Sci 14:43-70

Cane MA, Sarachik ES (1977) Forced baroclinic ocean motions: II. The linear equatorial bounded case. J Marine Res 35:395432

Cane MA, Zebiak SE (1985) A theory for El Niño and the Southern Oscillation. Science 228:1084-1087

Cane MA, Zebiak SE, Dolan SC (1986) Experimental forecasts of El Niño. Nature 321:827-832

Cane MA, Münnich M, Zebiak SE (1990) A study of self-excited oscillations of the tropical ocean-atmosphere system. Part I: Linear analysis. J Atmos Sci 47:1562-1577

Cess RD, Potter GL, Blanchet JP, Boer GJ, Ghan SJ, Kiehl JT, LeTreut H, Li Z-X, Liang X-Z, Mitchell JFB, Morcrette J-J, Randall DA, Riches MR, Roeckner E, Schlese U, Slingo A, Taylor KE, Washington WM, Wetherald RT, Yagai I (1989) Interpretation of cloud-climate feedback as produced by 14 atmospheric general circulation models. Science 245:513-516

Charnock H, Philander SGH (eds) (1989) The dynamics of the coupled atmosphere and ocean. Proceedings of a Royal Society Discussion Meeting. The Royal Society, London

Chao Y (1990) Seasonal and interannual variability in the tropical Pacific Ocean. PhD dissertation, Princeton University, USA

Cheng M-D, Arakawa A (1991) Inclusion of Convective downdrafts in the Arakawa-Schubert cumulus parameterization. In: Extended abstract volume, 19th Conference on Hurricane and Tropical Meteorology, May 6-10, 1991, Miami, Florida, pp 295-300. American Meteorological Soc, Boston, Mass, USA
Cubasch U (1985) The mean response of the ECMWF global model to the El Niño anomaly in extended range prediction experiments. Atmosphere-Ocean 23:43-66

Cubasch U, Santer BD, Maier-Reimer E, Böttinger M (1990) Sensitivity of a global coupled ocean atmosphere circulation model to a doubling of carbon dioxide. In: Pitcher EJ (ed) Science and engineering on supercomputers, Computational Mechanics Publications, Southampton, pp 347-352

Currie RG, Hameed S (1988) Evidence of quasi-bjennial oscillations in a general circulation model. Geophys Res Lett 165:649-652

Deardorff JW (1972) Parameterization of the planetary boundary layer for use in general circulation models. Mon Wea Rev 100:93-96

Deser C, Wallace JM (1990) Large-scale atmospheric circulation features of warm and cold episodes in the tropical Pacific. J Climate 3:1254-1281

Ellingson RG, Fouquart Y (1990) The intercomparison of radiation codes in climate models. World Meteorological Organization, Technical Document No. 371, WCRP-39, World Climate Research Programme, Geneva

Endoh M, Tokioka T, Nagai T (1991) Tropical Pacific sea surface temperature variations in a coupled atmosphere-ocean general circulation model. J Marine Systems 1:293-298

Fischer G (ed) (1987) Climate simulations with the ECMWF T21 model in Hamburg. Large scale atmospheric modelling Report No. 1, Meteorologisches Institut der Universität Hamburg, FRG

Gates WL, Han YJ, Schlesinger ME (1985) The global climate simulated by a coupled atmosphere-ocean general circulation model: preliminary results. In: Nihoul JCJ (ed) Coupled ocean-atmosphere models. Elsevier Oceanogr Ser 40, pp 131151

Gent PR (1991) The heat budget of the TOGA-COARE domain in an ocean model. J Geophys Res 96:3323-3330

Gent PR, Cane MA (1989) A reduced gravity, primitive equation model of the upper equatorial ocean. J Computational Phys 81:444-480

Ghan SJ, Lingaas JW, Schlesinger ME, Mobley RL, Gates WL (1982) A documentation of the OSU two-level atmospheric model. Report 35, Climatic Research Institute, Oregon State University, Corvallis, Oregon, USA

Ghil M, Vautard R (1991) Interdecadal oscillations and the warming trend in global temperature time series. Nature 350:324327

Gill AE (1980) Some simple solutions for heat induced tropical circulation. Quart J Roy Met Soc 106:447-462

Gill AE, Rasmusson EM (1983) The 1982-1983 climate anomaly in the equatorial Pacific. Nature 306:229-234

Goldenberg SB, O'Brien JJ (1981) Time and space variability of tropical Pacific wind stress. Mon Wea Rev 109:1190-1207

Gordon C (1989a) Comparison of surface fluxes in the tropical Pacific Ocean derived from an atmospheric GCM and from climatology. Tropical Ocean-Atmosphere Newsletter No. 51

Gordon C (1989b) Tropical ocean-atmosphere interactions in a coupled model. Phil Trans Roy Soc Lond A329:207-223

Gordon C, Corry RA (1991) An ocean model simulation of the seasonal cycle in the Tropical Pacific Ocean using climatological and modelled surface forcing. J Geophys Res 96C:847864

Goswami BN, Shukla J (1991) Predictability of a coupled oceanatmosphere model. J Climate 4:3-22

Graham NE, Barnett TP (1987) Sea surface temperature, surface wind divergence, and convection over tropical oceans. Science 238:657-659

Gutzler DS, Wood TM (1990) Structure of large-scale convective anomalies over tropical oceans. J Climate 3:483-496

Hameed S, Pittalwala I (1991) The North Pacific oscillation: observations compared with simulation in a general circulation model. Clim Dyn (in press)

Hameed S, Sperber KR, Cess RD (1989) Genesis of the Southern 
Oscillation within the atmosphere: illustration with general circulation models. Geophys Res Lett 16:691-694

Han YJ (1984a) A numerical world ocean general circulation model, Part I. Basic design and barotropic experiment. Dyn Atmos Ocean 8:107-140

Han YJ (1984b) A numerical world ocean general circulation model, Part II. A baroclinic experiment. Dyn Atmos Oceans 8:141-172

Harshvardhan, Davies R, Randall DA, Corsetti TG (1987) A fast radiation parameterization for general circulation models. $J$ Geophys Res 92:1009-1016

Hellerman S, Rosenstein M (1983) Normal monthly wind stress over the world ocean with error estimates. J Phys Oceanogr 13:1093-1104

Hirst AC (1986) Unstable and damped equatorial modes in simple coupled ocean-atmosphere models. J Atmos Sci 43:606-630

Hirst AC (1988) Slow instabilities in tropical ocean basin-global atmosphere models. J Atmos Sci 45:830-852

Hirst AC (1990) On simple coupled ocean-atmosphere models, equatorial instabilities and ENSO. Proc Int TOGA Scientific Conference, World Meteorological Organization, Technical Document No. 379, WCRP-43, World Climate Research Programme, Geneva

Horel JD (1982) The annual cycle in the tropical Pacific atmosphere and ocean. Mon Wea Rev 110:1863-1878

Ineson S, Gordon C (1989) Parameterization of the upper ocean mixed layer in a tropical ocean GCM. Dynamical Climatology Technical Note No. 74, UK Meteorological Office

Katayama A (1972) A simplified scheme for computing radiative transfer in the troposphere. Tech Rep No. 6, Dept Meteor, University of California, Los Angeles

Kattenberg A, Allaart MAF (1989) The effect of salinity on a tropical Pacific Ocean model. Ocean Modelling 83:2-4

Latif M (1987) Tropical ocean circulation experiments. J Phys Oceanogr 17:246-263

Latif M, Biercamp J, von Storch H (1988a) The response of a coupled ocean-atmosphere general circulation model to wind bursts. J Atmos Sci 45:964-979

Latif M, Biercamp J, von Storch H, Zwiers FW (1988b) A ten year climate simulation with a coupled ocean-atmosphere general circulation model. Max-Planck-Institut für Meteorologie, Report No. 21, Bundesstrasse 55, D-2000 Hamburg 13, FRG

Latif M, Biercamp J, von Storch M, McPhaden MJ, Kirk E (1990) Simulation of surface wind anomalies with an AGCM forced by observed SST. J Climate 5:509-521

Latif M, Villwock A (1990) Interannual variability as simulated in coupled ocean-atmosphere models. J Marine Systems 1:5160

Lau KM, Sheu PJ (1988) Annual cycle, quasi-biennial oscillation and Southern Oscillation in global precipitation. J Geophys Res 93:10975-10988

Lau NC (1985) Modelling the seasonal dependence of the atmospheric response to observed El Niños in 1962-76. Mon Wea Rev 113:1970-1996

Lau NC, Philander SGH, Nath MJ (1992) Simulation of ENSOlike phenomena with a low-resolution coupled GCM of the global ocean and atmosphere. J Climate (in press)

Levitus S (1982) Climatological atlas of the world ocean. NOAA Professional Paper Nr. 13, US Govt Printing Office, Washington DC

Lindzen RS, Nigam S (1987) On the role of sea surface temperature gradients in forcing low level winds and convergence in the tropics. J Atmos Sci 44:2418-2436

van Loon H (1984) The Southern Oscillation. Part III: associations with the trades and with the trough in the westerlies of the South Pacific Ocean. Mon Wea Rev 112:947-954

Louis JF (ed) ECMWF forecast model. Meteorological Bulletin, ECMWF, Shinfield Park, Reading, UK

Maier-Reimer E, Hasselmann K, Olbers D, Willebrand J (1982) An ocean circulation model for climate studies. Tech Rep, MPI für Meteorologie, Hamburg, FRG
Manabe S, Hahn DG (1981) Simulation of atmospheric variability. Mon Wea Rev 109:2260-2286

Manabe S, Stouffer RJ (1988) Two stable equilibria of a coupled ocean-atmosphere model. J Climate 1:841-866

McCreary JP (1976) Eastern tropical ocean response to changing wind systems with application to El Niño. J Phys Oceanogr 6:632-645

McCreary JP, Anderson DLT (1991) An overview of coupled ocean-atmosphere models of El Niño and the Southern Oscillation. J Geophys Res 96:3125-3150

Mechoso CR, Kitoh A, Moorthi S, Arakawa A (1987) Numerical simulations of the atmospheric response to a sea surface temperature anomaly over the equatorial eastern Pacific ocean. Mon Wea Rev 115:2936-2956

Mechoso CR, Fisher M, Ghil M, Halpern M, Spahr M (1990) Coupling experiments of an atmospheric and an oceanic GCM: Proc Int TOGA Scientific Conference, World Meteorological Organization, Technical Document No. 379, WCRP43, World Climate Research Programme, Geneva

Meehl GA (1989) The coupled ocean-atmosphere modeling in the tropical Pacific and Asian monsoon region. J Climate 2:11461163

Meehl GA (1990a) Seasonal cycle forcing of El Niño-Southern Oscillation in a global coupled ocean-atmosphere GCM. J Climate 3:72-98

Meehl GA (1990b) Development of global coupled ocean-atmosphere general circulation models. Clim Dyn 5:19-33

Meehl GA, Washington WM (1985) Sea surface temperatures computed by a simple ocean mixed layer coupled to an atmospheric model. J Phys Oceanogr 15:92-104

Meehl GA, Washington WM (1988) A comparison of soil moisture sensitivity in two global climate models. J Atmos Sci 45: 1476-1492

Meehl GA, Washington WM (1990) $\mathrm{CO}_{2}$ climate sensitivity and snow-sea-ice albedo parameterization in an atmospheric GCM coupled to a mixed-layer ocean model. Climatic Change 16:283-306

Meehl GA, Washington WM, Semtner AJ Jr (1982) Experiments with a global ocean model driven by observed atmospheric forcing. J Phys Oceanogr 12:301-312

Mellor GL, Yamada T (1974) A hierarchy of turbulence closure models for planetary boundary layers. J Atmos Sci 31:17911806

Neelin JD (1988) A simple model for surface stress and low-level flow in the tropical atmosphere driven by prescribed heating. Quart J Roy Met Soc 114:747-770

Neelin JD (1989) Interannual oscillations in an ocean general circulation model coupled to a simple atmosphere model. Phil Trans R Soc Lond 329A: 189-205

Neelin JD (1990) A hybrid coupled general circulation model for El Niño studies. J Atmos Sci 47:674-693

Neelin JD (1991) The slow sea surface temperature mode and the fast-wave limit: Analytic theory for tropical interannual oscillations and experiments in a hybrid coupled model. J Atmos Sci 48:584-606

Neelin JD, Held IM (1987) Modelling tropical convergence based on the moist static energy budget. Mon Wea Rev 115:3-12

Nihoul JCJ (ed) (1985) Coupled ocean-atmosphere models. Elsevier Oceanography Series, Amsterdam

Nihoul JCJ, Jamart B (eds) (1990) Coupled ocean-atmosphere modeling. J Marine Syst I (special issue)

Niiler PP, Kraus EB (1977) One-dimensional models of the upper ocean. In: Kraus EB (ed) Modelling and prediction of the upper layers of the ocean. Pergamon Press, New York, pp 143-172

Opsteegh JD, Murau R (1984) Description of a 15 layer steady state atmospheric model. University of Maryland Dept. of Meteorology Report No. SR-84-19

Pacanowski RC, Philander SGH (1981) Parameterization of vertical mixing in numerical models of the tropical oceans. J Phys Oceanogr $11: 1443-1451$ 
Palmer TN, Mansfield DA (1986) A study of wintertime circulation anomalies during past El Niño events using a high-resolution general circulation model. I: influence of model climatology. Quart J Roy Meteor Soc 112:613-638

Pan YH, Oort AH (1991) Correlation analyses between sea surface temperature anomalies in the eastern equatorial Pacific and the world ocean. Clim Dyn 4:191-205

Philander SGH (1990) El Niño, La Niña, and the Southern Oscillation. Academic Press, San Diego, USA

Philander SGH, Seigel AD (1985) Simulation of El Niño of 19821983. In: Nihoul JCJ (ed) Coupled ocean-atmosphere models. Elsevier, Amsterdam

Philander SGH, Yamagata T, Pacanowski RC (1984) Unstable air-sea interactions in the tropics. J Atmos Sci 41:604-613

Philander SGH, Hurlin WJ, Seigel AD (1987) Simulation of the seasonal cycle of the tropical Pacific Ocean. J Phys Oceanogr 17:1986-2002

Philander SGH, Lau NC, Pacanowski RC, Nath MJ (1989) Two different simulations of Southern Oscillation and El Niño with coupled ocean-atmosphere general circulation models. Phil Trans Roy Soc A329:167-178

Philander SGH, Pacanowski RC, Lau NC, Nath MJ (1992) Simulation of ENSO with a global atmospheric GCM coupled to a high-resolution, tropical Pacific ocean GCM. J Climate (in press)

Pittalwala I, Hameed S (1991) Simulation of the North Atlantic Oscillation in a general circulation model. Geophys Res Lett (in press)

Pollard D (1982) The performance of an upper-ocean model coupled to an atmospheric GCM: preliminary results. Climatic Research Institute, Report No. 31, Oregon State University, Corvallis, Oregon, USA

Randall D (1976) The interaction of the planetary boundary layer with large-scale circulations. $\mathrm{PhD}$ dissertation, University of California, Los Angeles, USA

Rasmusson EM, Carpenter TH (1982) Variations in the tropical sea surface temperature and surface wind fields associated with the Southern Oscillation/El Niño. Mon Wea Rev 110:354-384

Rasmusson EM, Carpenter TH (1983) The relationship between eastern equatorial Pacific sea-surface temperatures and rainfall over India and Sri Lanka. Mon Wea Rev 111:517-528

Rasmusson EM, Wang X, Ropelewski CF (1990) The biennial component of ENSO variability. J Marine Syst 1:71-96

Reynolds RW (1988) A real-time global sea surface temperature analysis. J Climate 1:75-86

Roeckner E, Dümenil L, Kirk E, Lunkeit F, Ponater M, Rockel B, Sausen R, Schlese U (1989). The Hamburg version of the ECMWF model (ECHAM). In: Boer GJ (ed) Research activities in atmospheric and oceanic modelling. CAS/JSC Working Group on Numerical Experimentation, No. 13, 7.1-7.4

Rosati A, Miyakoda K (1988) A general circulation model for upper ocean simulation. J Phys Oceanogr 18:1601-1626

Sausen R, Barthel K, Hasselmann K (1988) Coupled ocean-atmosphere models with flux correction. Clim Dyn 2:145-163

Schlesinger ME, Gates WL (1980) The January and July performance of the OSU two-level atmospheric general circulation model. J Atmos Sci 37:1914-1943

Schlesinger ME, Gates WL (1981) Preliminary analysis of the mean annual cycle and interannual variability simulated by the OSU two-level atmospheric general circulation model. Report No. 23, Climatic Research Institute, Oregon State University, USA

Schopf PS, Cane MA (1983) On equatorial dynamics, mixed layer physics and sea surface temperature. J Phys Oceanogr 13:917935
Schopf PS, Suarez MJ (1988) Vacillations in a coupled oceanatmosphere model. J Atmos Sci 45:549-566

Schopf PS, Suarez MJ (1990) Ocean wave dynamics and the time scale of ENSO. J Phys Oceanogr 20:549-566

Seager R, Zebiak SE, Cane MA (1988) A model of the tropical Pacific sea surface temperature climatology. J Geophys Res 93:1265-1280

Shukla J, Fennessey MJ (1988) Prediction of time-mean atmospheric circulation and rainfall: influence of Pacific sea surface temperature anomaly. J Atmos Sci 45:9-28

Slingo A, Wilderspin RC, Smith RNB (1991) The effect of improved physical parameterization on simulations of cloud and the earth's radiation budget. J Geophys Res (in press)

Sperber KR (1989) Southern Oscillation simulation in coupled ocean/atmosphere global climate models. Ph D Dissertation, State University of New York at Stony Brook, Stony Brook, New York, USA

Sperber KR, Hameed S (1991) Southern Oscillation in the OSU coupled upper ocean-atmosphere GCM. Clim Dyn (in press)

Sperber KR, Hameed S, Gates WL, Potter GL (1987) Southern Oscillation simulated in a global climate model. Nature 329:140-142

von Storch H (ed) (1988) Climate simulations with the ECMWF T21-model in Hamburg. Part II: Climatology and sensitivity experiments. Large scale atmospheric modelling Report No. 4, Meteorologisches Institut der Universität Hamburg, FRG

Suarez MJ, Schopf PS (1988) A delayed action oscillator for ENSO. J Atmos Sci 45:3283-3287

Suarez MJ, Arakawa A, Randall DA (1983) The parameterization of the planetary boundary layer in the UCLA general circulation model: formulation and results. Mon Wea Rev 111:22242243

Tokioka T et al. (1984) A description of the Meteorological Research Institute atmospheric general circulation model (MRIGCM-I). Technical Report of the MRI 13:1-249

Wallace JM, Mitchell TP, Deser C (1989) The influence of seasurface temperature on surface wind in the eastern equatorial Pacific: seasonal and interannual variability. J Climate 2:1492-1499

Washington WM, Meehl GA (1983) General circulation model experiments on the climatic effects due to a doubling and quadrupling of carbon dioxide concentration. J Geophys Res 88:6600-6610

Washington WM, Meehl GA (1984) Seasonal cycle experiment on the climate sensitivity due to a doubling of $\mathrm{CO}_{2}$ with an atmospheric general circulation model coupled to a simple mixedlayer ocean model. J Geophys Res 89:9475-9503

Washington WM, Meehl GA (1989) Climate sensitivity due to increased $\mathrm{CO}_{2}$ : experiments with a coupled atmosphere and ocean general circulation model. Clim Dyn 4:1-38

Williamson DL et al. (1987) Description of NCAR Community Climate Model (CCM1). NCAR/TN-285 + STR

World Climate Research Programme (1990) Proc Int TOGA Scientific Conference, World Meteorological Organization, Technial Document No. 379, WCRP-43, World Climate Research Programme, Geneva

Wyrtki K (1975) El Niño-the dynamic response of the equatorial Pacific Ocean to atmospheric forcing. J Phys Oceanogr 5:572584

Zebiak SE (1986) Atmospheric convergence feedback in a simple model for El Niño. Mon Wea Rev 114:1263-1271

Zebiak SE (1990) Intermediate models of ENSO. Proc Int TOGA Scientific Conference, World Meteorological Organization, Technical Document No. 379, WCRP-43, World Climate Research Programme, Geneva

Zebiak SE, Cane MA (1987) A model El Niño-Southern Oscillation. Mon Wea Rev 115:2262-2278 